\title{
Nickel-Based Superalloys for Advanced Turbine Engines: Chemistry, Microstructure, and Properties
}

\author{
Tresa M. Pollock \\ University of Michigan, Ann Arbor, Michigan 48109 \\ and \\ Sammy Tin \\ University of Cambridge, Cambridge, England CB2 3QZ, United Kingdom
}

\begin{abstract}
The chemical, physical, and mechanical characteristics of nickel-based superalloys are reviewed with emphasis on the use of this class of materials within turbine engines. The role of major and minor alloying additions in multicomponent commercial cast and wrought superalloys is discussed. Microstructural stability and phases observed during processing and in subsequent elevated-temperature service are summarized. Processing paths and recent advances in processing are addressed. Mechanical properties and deformation mechanisms are reviewed, including tensile properties, creep, fatigue, and cyclic crack growth.
\end{abstract}

\section{Introduction}

$\mathbf{N}$ ICKEL-BASED superalloys are an unusual class of metallic materials with an exceptional combination of hightemperature strength, toughness, and resistance to degradation in corrosive or oxidizing environments. These materials are widely used in aircraft and power-generation turbines, rocket engines, and other challenging environments, including nuclear power and chemical processing plants. Intensive alloy and process development activities during the past few decades have resulted in alloys that can tolerate average temperatures of $1050^{\circ} \mathrm{C}$ with occasional excursions (or local hot spots near airfoil tips) to temperatures as high as $1200^{\circ} \mathrm{C},{ }^{1}$ which is approximately $90 \%$ of the melting point of the material. The underlying aspects of microstructure and composition that result in these exceptional properties are briefly reviewed here. Major classes of superalloys that are utilized in gas-turbine engines and the corresponding processes for their production are outlined along with characteristic mechanical and physical properties.

\section{Superalloys in Gas-Turbine Engines}

Nickel-based superalloys typically constitute $40-50 \%$ of the total weight of an aircraft engine and are used most extensively in the combustor and turbine sections of the engine where elevated temperatures are maintained during operation. ${ }^{1}$ Creep-resistant turbine blades and vanes are typically fabricated by complex investment casting procedures that are essential for introduction of elaborate cooling schemes and for control of grain structure. Such components may contain equiaxed grains or columnar grains, or may be cast as single crystals, completely eliminating all high-angle grain boundaries. Because grain boundaries are sites for damage accumulation at high temperatures, the blades in the early stages of the turbine are typically single crystals, whereas the blades in the later (cooler) stages of the turbine are fabricated from equiaxed alloys. Structural components such as engine cases are also fabricated by investment casting processes. Turbine disks are fabricated via wrought processing approaches that either use cast ingots or consolidated superalloy powder performs. Exceptional combinations of strength, toughness, and crack-growth resistance can be achieved in these materials by close control of microstructure through the multiple stages of wrought processing. Table 1 lists the nominal composition of several common cast and wrought commercial superalloys utilized in gas-turbine engines.

\section{Constitution of Superalloys}

As is apparent from Table 1, although face-centered cubic (FCC) nickel is the major superalloy constituent, many alloys contain up to $40 \mathrm{wt} \%$ of a combination of five to ten other elements. The elements typically alloyed with nickel to form a superalloy are highlighted in Fig. 1.

The nickel-aluminum system is the binary basis for superalloy compositions. As the level of aluminum added to $\gamma$-nickel increases, a second precipitate phase forms. This phase has a nominal composition of $\mathrm{Ni}_{3} \mathrm{Al}$, is designated the $\gamma^{\prime}$ phase, and has an ordered intermetallic $\mathrm{L} 1_{2}$ crystal structure. Formation of the $\gamma^{\prime}$ phase occurs in the solid state as the supersaturated solid solution of $\gamma$-nickel

Tresa M. Pollock is the L.H. and F.E. Van Vlack Professor of Materials Science and Engineering at the University of Michigan, Ann Arbor, MI. She received a B.S. from Purdue University in 1984 and a Ph.D. from MIT in 1989. Dr. Pollock was employed at General Electric Aircraft Engines from 1989-1991, where she conducted research and development on high temperature alloys for aircraft turbine engines. She was a professor in the Department of Materials Science and Engineering at Carnegie Mellon University from 1991-1999. Her research interests are in the area of processing and properties of high temperature structural materials, including nickel-base alloys, intermetallics, coatings and composites. Professor Pollock is the President of The Minerals, Metals and Materials Society (TMS) and Associate Editor of Metallurgical and Materials Transactions. She is a Fellow of ASM International and has received the ASM International Research Silver Medal Award. Pollock was elected to the National Academy of Engineering in 2005 .

Sammy Tin is Professor of Mechanical, Materials and Aerospace Engineering at the Illinois Institute of Technology. Prior to joining the faculty at IIT, he served as the Deputy Director of the Rolls-Royce University Technology Partnership at the University of Cambridge, U.K. where he led an active group of graduate students and post-doctoral researchers working on a range of projects relating to processing and deformation of high-temperature structural materials. Professor Tin received his Ph.D. in Materials Science and Engineering from the University of Michigan in 2001. He also received an M.S. from Carnegie Mellon University and a B.S. from California Polytechnique State University, San Luis Obispo.

Received 16 June 2005; revision received 15 June 2005; accepted for publication 31 August 2005. Copyright (C) 2005 by the American Institute of Aeronautics and Astronautics, Inc. All rights reserved. Copies of this paper may be made for personal or internal use, on condition that the copier pay the $\$ 10.00$ per-copy fee to the Copyright Clearance Center, Inc., 222 Rosewood Drive, Danvers, MA 01923; include the code 0748-4658/06 \$10.00 in correspondence with the CCC. 
Table 1 Compositions of commercial Ni-based superalloys (wt. \%, bal. Ni)

\begin{tabular}{|c|c|c|c|c|c|c|c|c|c|c|c|c|c|c|c|}
\hline Alloy & $\mathrm{Cr}$ & Co & Mo & $\mathrm{W}$ & $\mathrm{Ta}$ & $\operatorname{Re}$ & $\mathrm{Nb}$ & $\mathrm{Al}$ & $\mathrm{Ti}$ & $\mathrm{Hf}$ & $\mathrm{C}$ & B & $\mathrm{Y}$ & $\mathrm{Zr}$ & Other \\
\hline \multicolumn{16}{|c|}{ Conventionally Cast Alloys } \\
\hline Mar-M246 & 8.3 & 10.0 & 0.7 & 10.0 & 3.0 & - & - & 5.5 & 1.0 & 1.50 & 0.14 & 0.02 & - & 0.05 & - \\
\hline Rene' 80 & 14.0 & 9.5 & 4.0 & 4.0 & - & - & - & 3.0 & 5.0 & - & 0.17 & 0.02 & - & 0.03 & - \\
\hline C1023 & 15.5 & 10.0 & 8.5 & - & - & - & - & 4.2 & 3.6 & - & 0.16 & 0.01 & - & - & - \\
\hline \multicolumn{16}{|c|}{ Directionally Solidified Alloys } \\
\hline IN792 & 12.6 & 9.0 & 1.9 & 4.3 & 4.3 & - & - & 3.4 & 4.0 & 1.00 & 0.09 & 0.02 & - & 0.06 & - \\
\hline PWA 1480 & 10.0 & 5.0 & - & 4.0 & 12.0 & - & - & 5.0 & 1.5 & - & - & - & - & - & - \\
\hline Rene' $^{\prime}$ N4 & 9.8 & 7.5 & 1.5 & 6.0 & 4.8 & - & 0.5 & 4.2 & 3.5 & 0.15 & 0.05 & 0.00 & - & - & - \\
\hline CMSX-3 & 8.0 & 5.0 & 0.6 & 8.0 & 6.0 & - & - & 5.6 & 1.0 & 0.10 & - & - & - & - & - \\
\hline \multicolumn{16}{|c|}{ Second-Generation Single-Crystal Alloys } \\
\hline PWA 1484 & 5.0 & 10.0 & 2.0 & 6.0 & 9.0 & 3.0 & - & 5.6 & - & 0.10 & - & - & - & - & - \\
\hline Rene' $^{\prime}$ 5 & 7.0 & 7.5 & 1.5 & 5.0 & 6.5 & 3.0 & - & 6.2 & - & 0.15 & 0.05 & 0.00 & 0.01 & - & - \\
\hline \multicolumn{16}{|c|}{ Wrought Superalloys } \\
\hline IN 718 & 19.0 & - & 3.0 & - & - & - & 5.1 & 0.5 & 0.9 & - & - & 0.02 & - & - & $18.5 \mathrm{Fe}$ \\
\hline Rene' $^{\prime} 41$ & 19.0 & 11.0 & 10.0 & - & - & - & - & 1.5 & 3.1 & - & 0.09 & 0.005 & - & - & - \\
\hline Nimonic 80A & 19.5 & - & - & - & - & - & - & 1.4 & 2.4 & - & 0.06 & 0.003 & - & 0.06 & - \\
\hline Waspaloy & 19.5 & 13.5 & 4.3 & - & - & - & - & 1.3 & 3.0 & - & 0.08 & 0.006 & - & - & - \\
\hline Udimet 720 & 17.9 & 14.7 & 3.0 & 1.3 & - & - & - & 2.5 & 5.0 & - & 0.03 & 0.03 & - & 0.03 & - \\
\hline \multicolumn{16}{|c|}{ Powder-Processed Superalloys } \\
\hline Rene' $^{\prime} 95$ & 13.0 & 8.0 & 3.5 & 3.5 & - & - & 3.5 & 3.5 & 2.5 & - & 0.065 & 0.013 & - & 0.05 & - \\
\hline Rene' $^{\prime} 88$ DT & 16.0 & 13.0 & 4.0 & 4.0 & - & - & 0.7 & 2.1 & 3.7 & - & 0.03 & 0.015 & - & - & - \\
\hline N18 & 11.2 & 15.6 & 6.5 & - & - & - & - & 4.4 & 4.4 & 0.5 & 0.02 & 0.015 & - & 0.03 & - \\
\hline IN100 & 12.4 & 18.4 & 3.2 & - & - & - & - & 4.9 & 4.3 & - & 0.07 & 0.02 & & 0.07 & \\
\hline
\end{tabular}

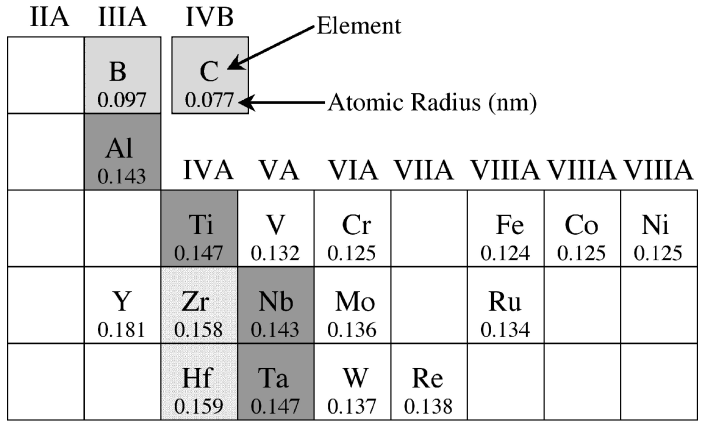

$\gamma$ ' former $\square$ Minor alloying additions $\square \gamma$ former

Fig. 1 Alloying elements present in Ni-based superalloys (adapted from Ref. 2).

is cooled below its equilibrium solvus temperature. Hence, the precipitation and growth kinetics of the $\gamma^{\prime}$ phase are highly sensitive to the rate at which the alloy is cooled through the solvus temperature. A unimodal distribution of fine $\gamma^{\prime}$ precipitates $(300-500 \mathrm{~nm})$ is typically associated with cooling rates in excess of $\sim 40 \mathrm{~K} / \mathrm{min}$, whereas slower cooling rates tend to promote the formation of multiple populations of $\gamma^{\prime}$ precipitates consisting of a combination of large $(>500 \mathrm{~nm})$ and small $(<50 \mathrm{~nm})$ precipitates. The presence of a high-volume fraction of the $\gamma^{\prime}$ phase is key to strengthening, as is discussed in more detail in Sec. V. These two phases remain the major constituents of the superalloy microstructure, even with the addition of six to ten additional elements. Figure 2 shows a typical two-phase $\gamma-\gamma^{\prime}$ microstructure for a single-crystal turbine-blade alloy. In general, refractory alloying elements with large differences in electronic structure and atomic radii compared to $\mathrm{Ni}$, such as $\mathrm{Mo}$, $\mathrm{W}, \mathrm{Nb}$, and $\mathrm{Re}$, are added for solid-solution strengthening of the $\gamma$ phase. Additions of $\mathrm{Ti}, \mathrm{Ta}$, and $\mathrm{Nb}$ contribute to the formation and strengthening of the $\mathrm{Ni}_{3}(\mathrm{Al}, \mathrm{Ti}, \mathrm{Ta}, \mathrm{Nb}) \gamma^{\prime}$ phase. ${ }^{2,3}$ Additions of iron form the basis of an important group of Ni-Fe superalloys, with the most common alloy being IN 718 (Table 1); although this class of superalloys is not discussed in any detail here, there is extensive

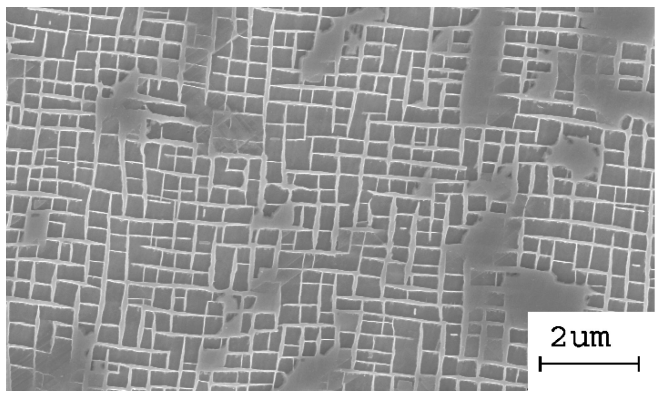

Fig. 2 Microstructure of an Ni-based superalloy single crystal revealing a high volume fraction of $\gamma^{\prime}$ precipitates, which have a cuboidal morphology (courtesy of $L$. Rowland).

information available on microstructure, properties, and processing of this class of alloys. ${ }^{4}$ Additions of $\mathrm{Cr}$, Y, and La typically improve oxidation and/or corrosion behavior, which is optimized via formation of an adherent slow-growing alumina scale.

Several elements are added in small quantities for control of grain structure and mechanical properties that are strongly influenced by grain boundaries. Minor additions of $\mathrm{B}, \mathrm{C}, \mathrm{Hf}$, and $\mathrm{Zr}$ tend to result in the formation of borides or carbides, often located at the grain boundaries. These elements are important for control of grain size during wrought processing and for minimization of damage accumulation at grain boundaries in service. ${ }^{5}$ Carbon exhibits a high affinity for elements such as $\mathrm{Hf}, \mathrm{Zr}$, Ta, Ti, Nb, W, Mo, V, and $\mathrm{Cr}$ and tends to form primary $\mathrm{MC}$ (where $\mathrm{M}=$ metal atom) carbides directly from the liquid during solidification of Ni-based superalloys. Some general characteristics of selected MC carbide phases are listed in Table 2. Depending on the composition of the primary MC carbide and the constituent elements present in the alloy, subsequent solid-state transformation may decompose the $\mathrm{MC}$ carbide into a variety of $\mathrm{M}_{23} \mathrm{C}_{6}, \mathrm{M}_{6} \mathrm{C}$, and $\mathrm{M}_{7} \mathrm{C}_{3}$ carbides during heat treatment or in service. ${ }^{6}$ For example, $\mathrm{Cr}$ from the matrix can potentially react with the less-stable $\mathrm{TiC}$ and $\mathrm{NbC}$ carbides to form a series of $\mathrm{M}_{23} \mathrm{C}_{6}, \mathrm{M}_{6} \mathrm{C}$, and $\mathrm{M}_{7} \mathrm{C}_{3}$ carbides. As the primary $\mathrm{MC}$ carbides are 
Table 2 Characteristic properties of selected refractory carbides

\begin{tabular}{lccrc}
\hline \hline Carbide & Crystal structure & $\begin{array}{c}\Delta \mathrm{H} \text { at } 298 \mathrm{~K}, \\
\text { eV/atom }\end{array}$ & $\begin{array}{c}\text { Density, } \\
\mathrm{g} / \mathrm{cm}^{3}\end{array}$ & $\begin{array}{c}\text { Lattice } \\
\text { parameter, } \AA\end{array}$ \\
\hline TiC & B1 $(\mathrm{NaCl})$ & 1.91 & 4.91 & 4.328 \\
$\mathrm{ZrC}$ & $\mathrm{B} 1(\mathrm{NaCl})$ & 2.04 & 6.59 & 4.698 \\
$\mathrm{HfC}$ & $\mathrm{B} 1(\mathrm{NaCl})$ & 2.17 & 12.67 & 4.640 \\
$\mathrm{VC}$ & $\mathrm{B} 1(\mathrm{NaCl})$ & 1.06 & 5.05 & 4.166 \\
$\mathrm{NbC}$ & $\mathrm{B} 1(\mathrm{NaCl})$ & 1.46 & 7.79 & 4.470 \\
$\mathrm{TaC}$ & $\mathrm{B} 1(\mathrm{NaCl})$ & 1.48 & 14.50 & 4.456 \\
$\mathrm{CrC}$ & $\mathrm{B} 1(\mathrm{NaCl})$ & -0.01 & & \\
$\mathrm{MoC}$ & Hexagonal & 0.13 & 9.06 & a: $2.932 \mathrm{c:}: 10.97$ \\
WC & Hexagonal & 0.42 & 15.80 & a: 2.906 c: 2.837 \\
\hline
\end{tabular}

Table 3 Compositions of the constitutent phases, wt \%

\begin{tabular}{lrrrrrrrrrr}
\hline \hline Alloy/Phase & $\mathrm{Al}$ & $\mathrm{Co}$ & $\mathrm{Cr}$ & $\mathrm{Mo}$ & $\mathrm{W}$ & $\mathrm{Ta}$ & $\mathrm{Ti}$ & $\mathrm{Re}$ & $\mathrm{V}$ & $\mathrm{Ni}$ \\
\hline Rene' $^{\prime} \mathrm{N} 5 / \gamma$ & 2.3 & 12.1 & 15.0 & 2.7 & 5.3 & 0.4 & - & 7.6 & - & $\mathrm{Bal}$ \\
Rene' $^{\prime} 5 / \gamma^{\prime}$ & 7.5 & 4.5 & 2.4 & 0.8 & 4.0 & 3.1 & - & 0.5 & - & $\mathrm{Bal}$ \\
IN100/ $\gamma$ & 4.5 & 20.6 & 14.8 & 3.2 & - & - & 2.7 & - & 0.7 & $\mathrm{Bal}$ \\
$\mathrm{IN} 100 / \gamma^{\prime}$ & 6.8 & 11.8 & 4.1 & 1.6 & - & - & 7.6 & - & 0.8 & $\mathrm{Bal}$ \\
\hline
\end{tabular}

consumed, the depletion of $\mathrm{Cr}$ from the matrix surrounding the carbides results in the formation of a layer of $\gamma^{\prime}$ at the carbide interface. Because these carbides occupy a significantly larger volume along the grain boundaries and are often interconnected, particularly if they form with a script morphology (Fig. 3), potential degradation of the mechanical properties may occur when the MC carbides undergo this phase transformation. Although carbides may serve as crack-initiation sites during fatigue (in the absence of other more major types of defects), ${ }^{7}$ the presence of discrete carbides at the grain boundaries inhibits sliding and damage accumulation during high-temperature creep. ${ }^{5}$

Other "minor" elements also play an important role in superalloy metallurgy. During melting of Ni-based superalloys, unavoidable impurities present in the elemental additions or revert material in trace amounts are often found in the final product. The influence of alloy cleanliness on structural properties has been the subject of many detailed investigations. ${ }^{8,9}$ Advances in vacuum melting technology have minimized the levels of undesirable low-meltingpoint elements ${ }^{10}$ such as $\mathrm{Pb}, \mathrm{Bi}, \mathrm{Se}, \mathrm{Ag}, \mathrm{As}, \mathrm{Sb}, \mathrm{Cu}, \mathrm{Te}$, and $\mathrm{S}$. Sulfur, which is often the most difficult to control, is a deleterious impurity that adversely affects mechanical properties and oxidation resistance. Conventional methods of minimizing the content of $\mathrm{S}$ in the alloy consist of melting in $\mathrm{MgO}-\mathrm{Al}_{2} \mathrm{O}_{3}$-lined crucibles to form $\mathrm{MgS}$, which can then be removed from the melt.

Thermodynamic driving forces typically result in a preferential partitioning of individual alloying elements to either the $\gamma$ or $\gamma^{\prime}$ phases. Table 3 shows the composition of the phases in the turbineblade alloy Rene' $5^{11}$ and the turbine-disk alloy IN100. ${ }^{12}$ From these data, it is apparent that $\mathrm{Re}, \mathrm{Mo}, \mathrm{Cr}$, and Co preferentially partition to the matrix gamma phase, whereas $\mathrm{Ti}$, Ta, and $\mathrm{Al}$ partition to the precipitate phase. Certain elements, such as $\mathrm{W}$ and $\mathrm{Ru}$, are soluble within both the $\gamma$ and $\gamma^{\prime}$ phases and are typically much more evenly distributed between the two phases. ${ }^{13}$ Element partitioning is an important alloy-design consideration because the compositions of the constituent phases will impact both the mechanical and environmental characteristics of the alloy. Because the precipitate and matrix phases are crystallographically coherent, the compositions of the phases influence their lattice parameters and precipitate-matrix misfit, $\delta$ :

$$
\delta=\frac{a_{\gamma^{\prime}}-a_{\gamma}}{\frac{1}{2}\left(a_{\gamma^{\prime}}+a_{\gamma}\right)}
$$

where $a_{\gamma^{\prime}}$ and $a_{\gamma}$ are the lattice parameters of the $\gamma^{\prime}$ and $\gamma$ phases, respectively. The misfit will result in initial internal stresses, which in concert with the high degree of elastic anisotropy, will strongly influence precipitate shapes and resultant mechanical properties. ${ }^{14-23}$ Precipitates are typically spherical in alloys with near-zero misfit and become cuboidal in shape as the magnitude of the misfit approaches $|\delta| \approx 0.3$ (Ref. 20).

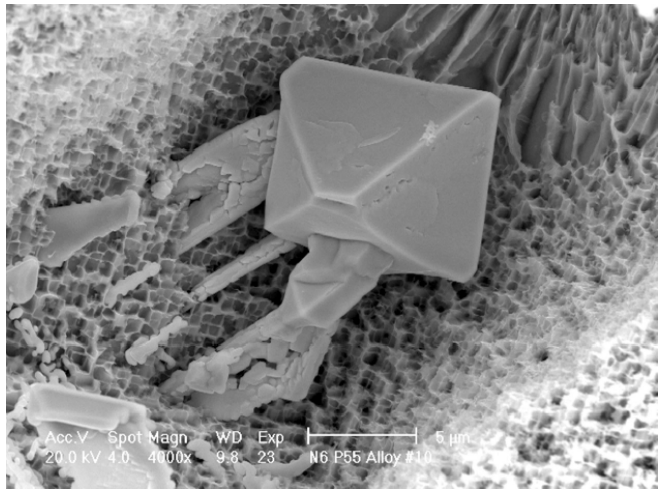

a)

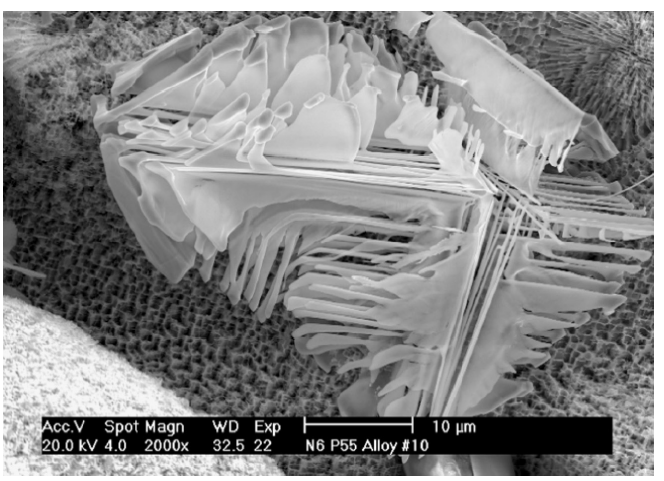

b)

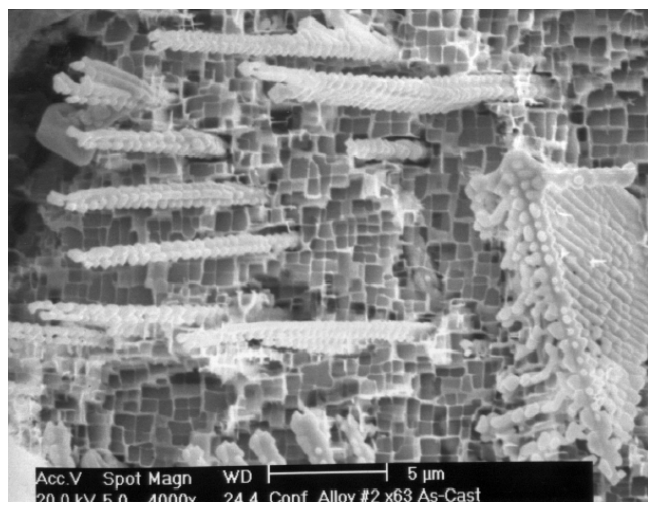

Fig. 3 SEM micrographs of a) blocky, b) script, and c) nodular MC carbides contained within the interdendritic regions of carboncontaining Ni-based superalloys.

A major concern in the design of new alloys and in the definition of specification limits for the acceptable range of individual alloying elements is the avoidance of a class of phases known as topologically closed-packed phases (TCPs). These phases are typically rich in refractory alloying elements and possess complex crystal structures characterized by close-packed layers of atoms (atomic coordination number $>12$ ). Examples of phases typically considered TCPs include the orthorhombic $\mathrm{P}$ phase, the tetragonal $\sigma$ phase, the rhombohedral $\mathrm{R}$, and rhombohedral $\mu$ phases. ${ }^{24-28}$ The TCP phases often form "basket-weave" sheets that are aligned with the octahedral planes in the FCC nickel matrix, Fig. 4. Similarities in the composition and crystallography of the various TCP phases allows these precipitates to develop as mixed structures consisting of a number of different phases. ${ }^{28}$ The TCP phases are detrimental because they deplete strengthening elements from the microstructure and/or serve as crack-initiation sites during cyclic loading. ${ }^{24-26}$ Precipitation kinetics for these phases are often very sluggish, resulting in precipitation only after extended times in service. New alloy-design tools based on the Calphad method ${ }^{29-32}$ are increasingly used in the 


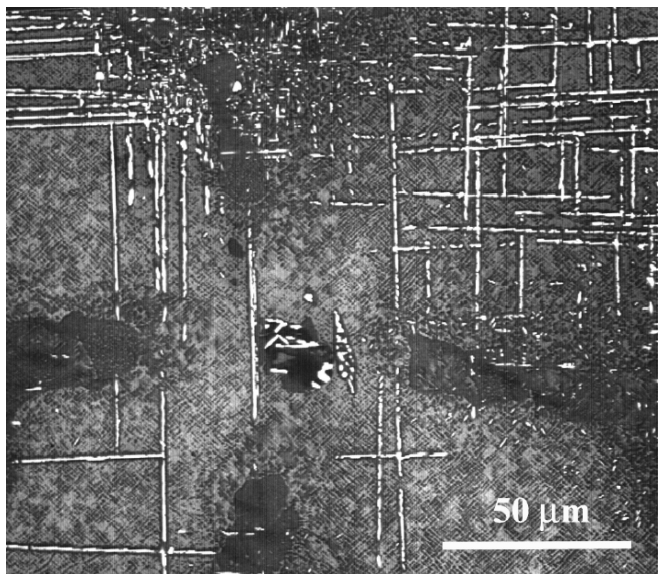

a)

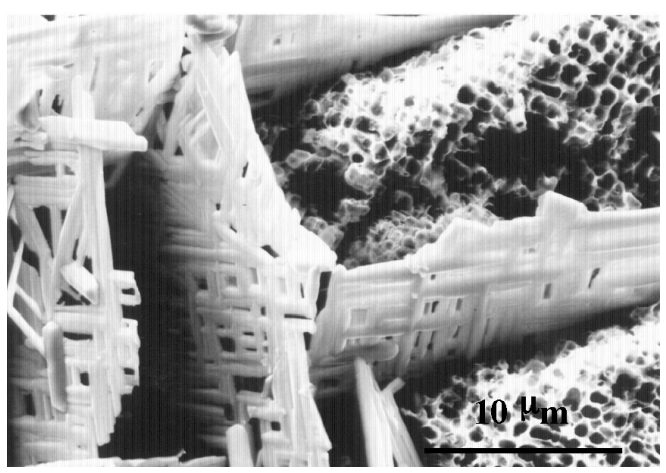

b)

Fig. 4 Ni-based superalloys containing elevated levels of refractory elements are prone to the precipitation of various TCP phases when exposed to elevated temperatures: a) refractory-rich TCPs (bright contrast) in a two-dimensional polished section and b) a three-dimensional view of interwoven sheets of TCPs in a partially extracted sample.

design of new alloys and to establish or modify specification ranges for existing alloys to avoid such deleterious phases. The ability to predict phase compositions and their ranges of stability is sensitively dependent on the development of thermodynamic models for these complex intermetallic phases and on the availability of databases to validate the modeling.

\section{Processing of Superalloys}

Superalloy processing begins with the fabrication of large ingots that are subsequently used for one of three major processing routes: 1) remelting and subsequent investment casting, 2) remelting followed by wrought processing, or 3) remelting to form superalloy powder that is subsequently consolidated and subjected to wrought processing operations. Ingots are fabricated by vacuum induction melting (VIM) in a refractory crucible to consolidate elemental and/or revert materials to form a base alloy. Although selected alloys can potentially be melted in air/slag environments using electric arc furnaces, VIM melting of superalloys is much more effective in the removal of low-melting-point trace contaminants. Following the vaporization of the contaminants, the carbon boil reaction is used to deoxidize the melt before the addition of the reactive $\gamma^{\prime}$-forming elements such as $\mathrm{Ti}, \mathrm{Al}$, and Hf. Once the desired alloy composition of the VIM ingot is attained, the solidified ingot is then subsequently subjected to additional melting or consolidation processes that are dependent upon the final application of the material. Charge weights of VIM ingots may range from $\sim 2500 \mathrm{~kg}$ to in excess of $27,500 \mathrm{~kg} .{ }^{33}$

Considering the stringent requirements for minimizing defects in turbine-engine components, a detailed understanding of structure evolution in each of these processing paths is essential. In the following sections, we briefly review the processing approaches and

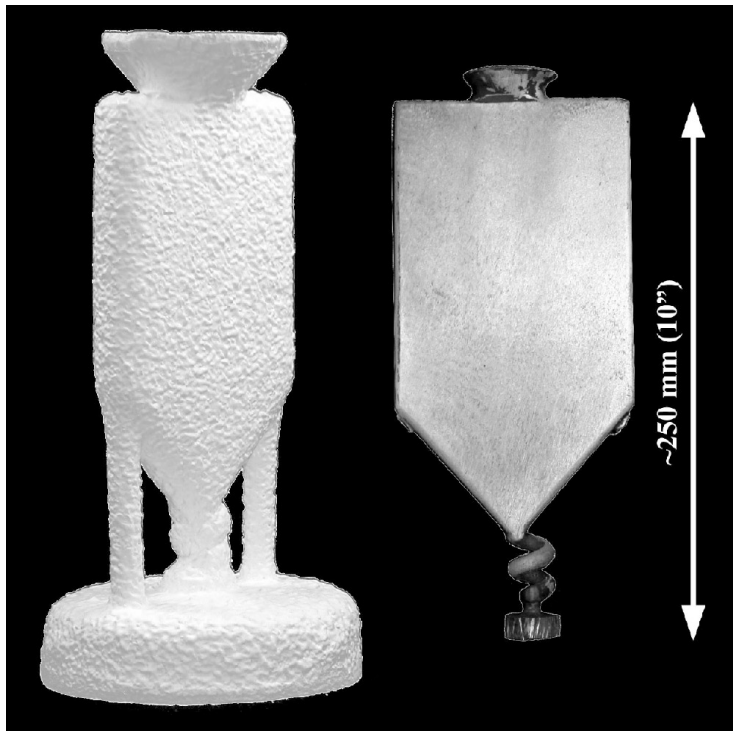

Fig. 5 Ceramic investment casting mold with single-crystal starter at the bottom of the plate and single-crystal plate following directional solidification and removal of ceramic mold (courtesy of A. J. Elliott).

aspects of superalloy structure that influence properties. Mechanical properties are discussed in more detail in Sec. V.

\section{A. Cast Superalloys}

Investment casting is the primary casting process for fabrication of superalloy components with complex shapes, including blades and vanes. Ceramic molds containing alumina, silica, and/or zirconia are utilized in this process (Fig. 5). The molds are fabricated by progressive buildup of ceramic layers around a wax pattern of the cast component. Ceramic cores can be embedded in the wax to obtain complex internal cooling structures. A thermal cycle removes the wax, and the mold is filled with remelted superalloy in a preheated vacuum chamber to obtain a shaped casting. The single-use mold is removed once the alloy has cooled to room temperature.

Castings may be equiaxed, columnar grained, or single crystal. Equiaxed castings solidify fairly uniformly throughout their volume, whereas columnar and single-crystal castings are withdrawn from a hot zone in the furnace to a cold zone at a controlled rate. Following initial solidification, castings are subjected to a series of subsequent heat-treatment cycles that serve to reduce segregation, establish one or more size populations of $\gamma^{\prime}$ precipitates, modify the structure of grain boundary phases (particularly carbides), and/or assist in the application of coatings.

In all casting processes, the final structure (and therefore properties) of the material are sensitive to the thermal conditions present during solidification of the casting. Solidification is dendritic in character, and the primary and secondary dendrite arm spacings are dependent on cooling rate, $G^{*} R$ (Fig. 6). Associated with the dendritic solidification is segregation of the constituent alloying elements. The extent of segregation is quantified by the distribution coefficient $k$ where

$$
k=C_{s} / C_{l}
$$

where $C_{s}$ is the local composition of the solid and $C_{l}$ is the local composition of the liquid. Considering the requirement for mass balance plus some degree of back diffusion in the solid during solidification, the variation in solid composition as a function of fraction solid $f_{s}$ from the beginning of solidification (at the dendrite core) to the end of solidification (in the interdendritic region) can be described by the modified Scheil equation ${ }^{34}$ :

$$
C_{s}=k C_{o}\left[1-(1-2 \alpha k) f_{s}\right]^{(k-1) /(1-2 \alpha k)}
$$

where $C_{o}$ is the nominal alloy composition and $\alpha$ is the Fourier number. 
Table 4 Ranges of distribution coefficients for second- and third-generation alloys and corresponding densities of pure elements at $20^{\circ} \mathrm{C}$

\begin{tabular}{lcccccc}
\hline \hline & $\mathrm{Al}$ & $\mathrm{Cr}$ & $\mathrm{Co}$ & $\mathrm{Ta}$ & $\mathrm{W}$ & $\mathrm{Re}$ \\
\hline Distribution coefficient, $k$ & $0.81-0.95$ & $1.05-1.17$ & $1.03-1.13$ & $0.67-0.80$ & $1.28-1.58$ & $1.23-1.60$ \\
Density at $20^{\circ} \mathrm{C}^{\mathrm{a}}$ & 2.7 & 7.2 & 8.8 & 16.7 & 19.3 & 21.0 \\
\hline \hline
\end{tabular}

${ }^{\mathrm{a}}$ Density of pure $\mathrm{Ni}=8.9 \mathrm{gm} / \mathrm{cm}^{3}$

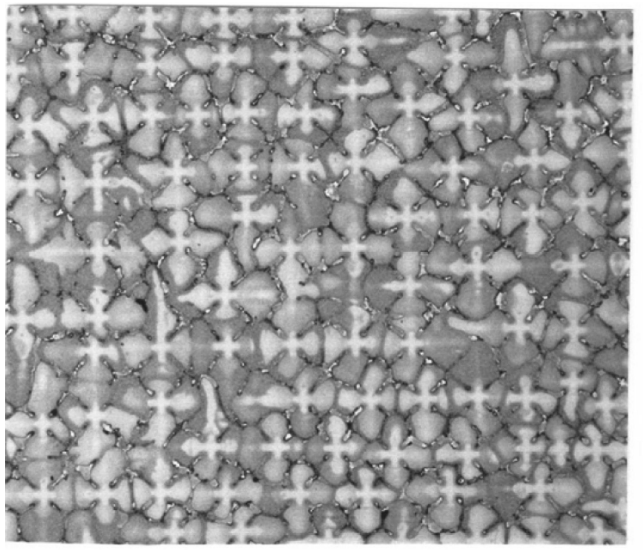

PDAS $=166$ microns

$\mathbf{G}^{*} \mathbf{R}=0.77^{\circ} \mathrm{C} / \mathrm{sec}$

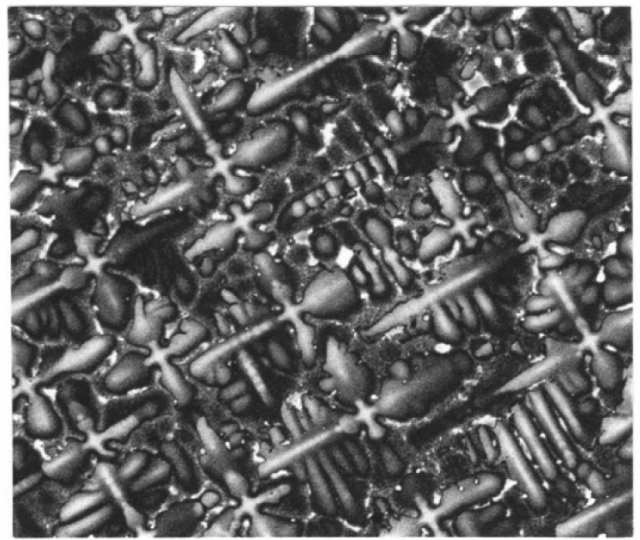

PDAS $=361$ microns

$G^{*} R=0.07^{\circ} \mathrm{C} / \mathrm{sec}$

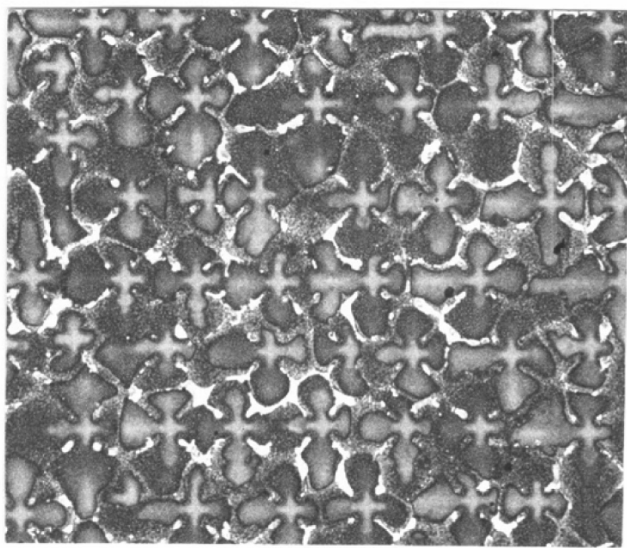

PDAS $=294$ microns

$G^{*} \mathbf{R}=0.13^{\circ} \mathrm{C} / \mathrm{sec}$

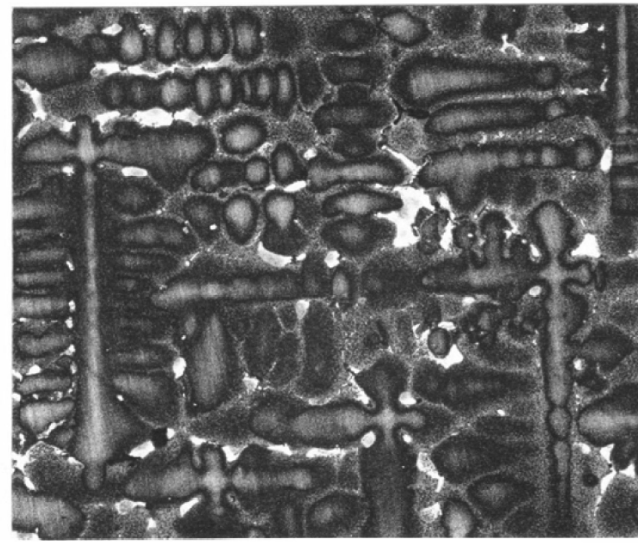

PDAS $=686$ microns

$G^{*} \mathbf{R}=0.01^{\circ} \mathrm{C} / \mathrm{sec}$

Fig. 6 Variation in dendrite morphology and primary dendrite arm spacing (PDAS) with cooling rate (G*R) during solidification.

In recent years segregation in multicomponent superalloys has received significant attention because of adverse effects of segregating elements on grain defect formation during solidification of advanced alloys. ${ }^{34-37}$ An example of the variation of Ta content across the dendritic structure of Alloy SX-3 (5.7Al-4.0Cr-11.5Co-5.0Re6.0Ta-5.0W-Bal $\mathrm{Ni}^{38}$ ) is shown in Fig. 7. Note that the modified Scheil equation provides a good estimate of the segregation tendencies of Ta $(k=0.79, \alpha=0.01)$, except at the lowest and highest solid fractions, where the sampling error of the local chemistry is more significant. Table 4 shows the range of values of distribution coefficients of individual elements measured in a large set of alloys characteristic of second- and third-generation single-crystal alloys. ${ }^{35}$ Note that values of the distribution coefficient closer to 1.0 are desirable with respect to minimizing segregation and that Ta, W, and Re tend to most strongly segregate in the as-cast microstructure. Again, before using in service, the as-cast components are often subjected to complex heat treatments designed to reduce or eliminate these solidification-induced compositional gradients and to establish a controlled size and distribution of precipitates.

\section{B. Directionally Solidified Alloys}

Although cast Ni-based superalloys have inherently good hightemperature properties to begin with, these properties can be improved upon through processing. The creep-rupture resistance of

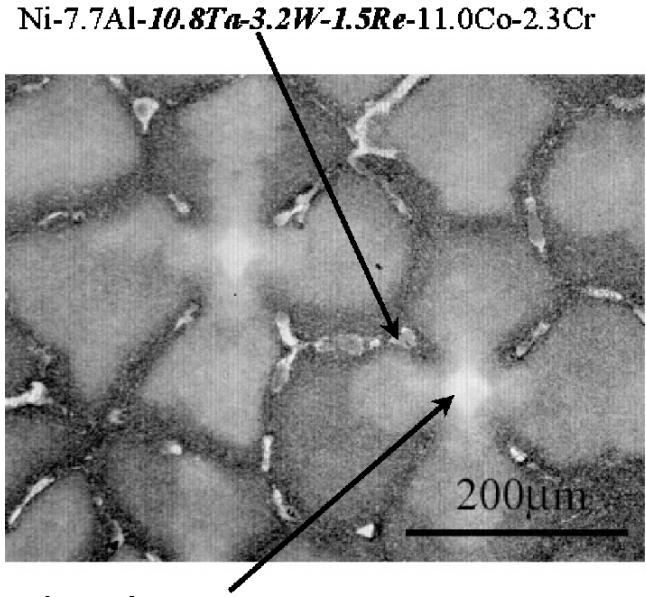

Ni-4.9Al-5.2Ta-6.7W-11.0Re-14.0Co-5.0Cr

Fig. 7 Dendritic microsegregation leads to the formation of significant compositional gradients within the as-cast structure of alloy SX-3 (with overall composition of Ni-5.7Al-4.0Cr-11.5Co-5.0Re-6.0Ta$5.0 \mathrm{~W}$ wt.\%). Elevated levels of Ta correspond to the interdendritic regions of the microstructure. The dendrite core contains elevated levels of Re. 


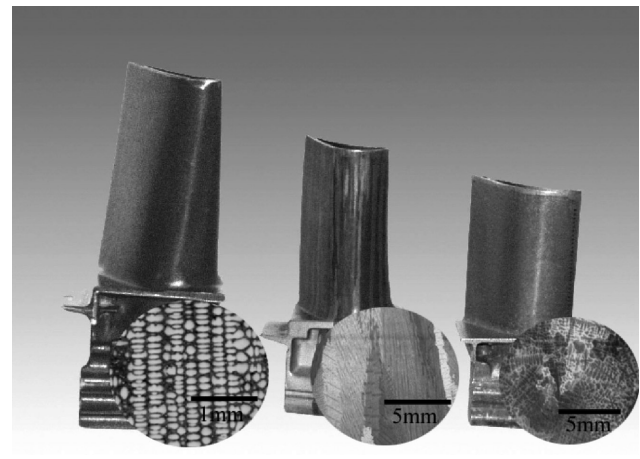

Fig. 8 Grain structures of single-crystal, directionally solidified, conventionally cast turbine blades.
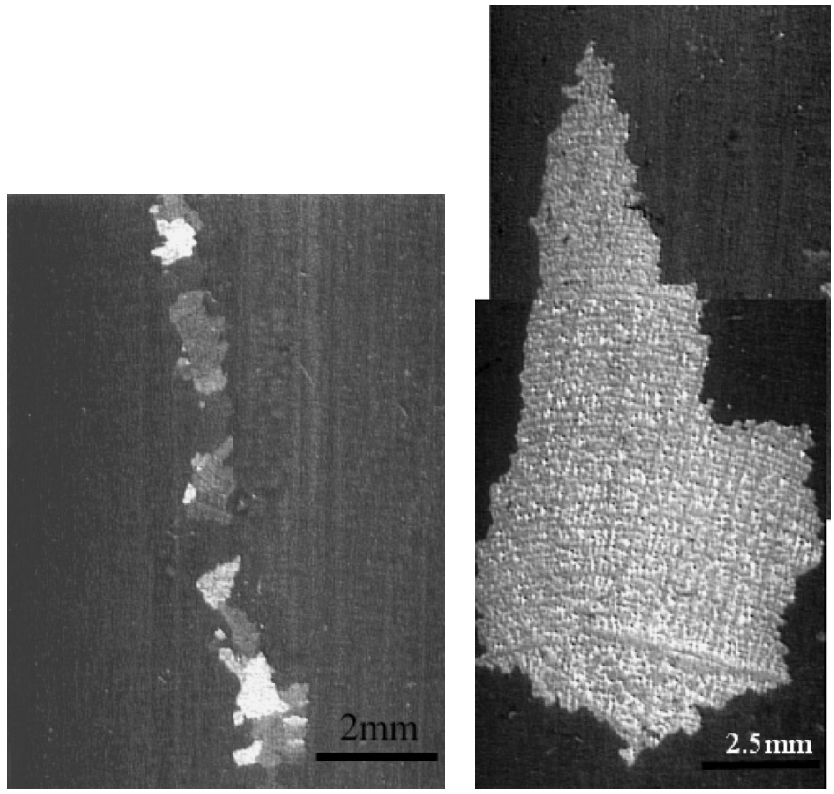

a)

b)

Fig. 9 Macroscopic chemistry-sensitive grain defects present on the surface of single-crystal Ni-based superalloy castings, including a) freckles and b) a misoriented grain.

Ni-based superalloys can be enhanced by orienting the grain boundaries parallel to the applied-stress direction or by removing the grain boundaries entirely (Fig. 8). Nickel-based alloys are directionally solidified into columnar-grained or single-crystal forms by withdrawing an investment mold downward through a radiation baffle from a high-temperature furnace at moderate thermal gradients $G$ and withdrawal rates $R$, in the range of 10 to $100^{\circ} \mathrm{C} / \mathrm{cm}$ and 5 to $40 \mathrm{~cm} / \mathrm{hr}$, respectively. By maintaining a unidirectional thermal gradient, preferential, oriented grain growth occurs. Because Ni-based superalloys exhibit cubic symmetry, these processing conditions encourage solidification along the orthogonal $\langle 001\rangle$ crystallographic orientations. The $\langle 001\rangle$ dendrites aligned most favorably with the thermal gradient tend to grow rapidly, whereas the superheated bulk liquid prevents the formation of equiaxed grains ahead of the solidifying interface. Consequently, directionally solidified components typically consist of a number of columnar $\langle 001\rangle$ grains aligned parallel to the solidification direction (Fig. 8) or when a grain selector is used (Fig. 5), $\langle 001\rangle$ oriented dendrites within a single crystal.

With directional solidification processing, several types of chemistry-sensitive grain defects may develop. ${ }^{33}$ The two most common grain defects that cause rejection of directionally solidified production components are freckle chains and misoriented grains (Fig. 9). Freckle-type defects, first studied in superalloys by Giamei et al. ${ }^{39,40}$ arise because of convective instabilities in the mushy zone that develop as a result of density inversions created by progressive segregation of individual alloying elements during solidification. The fluid flow within "channels" that develop be-
Table 5 Compositions of freckles and white spot defects in IN718

\begin{tabular}{lcccccccc}
\hline \hline Composition (wt\%) & $\mathrm{Al}$ & $\mathrm{Ti}$ & $\mathrm{Cr}$ & $\mathrm{Fe}$ & $\mathrm{Ni}$ & $\mathrm{Nb}$ & $\mathrm{Mo}$ & $\mathrm{Si}$ \\
\hline Nominal IN718 & 0.5 & 0.9 & 19.0 & 18.5 & $\mathrm{Bal}$ & 5.1 & 3.0 & 0.2 \\
Freckle & 0.43 & 1.33 & 17.4 & 15.2 & $\mathrm{Bal}$ & 9.43 & 3.51 & 0.16 \\
Whites spot & 0.41 & 0.62 & 17.7 & 19.2 & $\mathrm{Bal}$ & 2.96 & 3.2 & 0.19 \\
\hline
\end{tabular}

cause of these instabilities ${ }^{41,42}$ results in fragmentation of dendrite arms, producing a small chain of equiaxed grains aligned approximately parallel to the solidification direction. Freckles are enriched in elements that segregate to the interdendritic region during solidification and thus differ in composition from the base alloy. ${ }^{38}$ Freckle formation is promoted by low cooling rates, (low thermal gradients) and corresponding large dendrite arm spacings ${ }^{33,38}$ for a fixed alloy composition. Misoriented grains differ from freckles in that they have the same nominal composition as the base alloy but are typically larger and elongated along the solidification direction. Misoriented grains possessing high-angle grain boundaries with respect to the parent crystal form under the same alloy and process conditions as freckles, suggesting that thermosolutal convection and fragmentation also contribute to their formation. ${ }^{38}$ The high-angle boundaries associated with these defects serve as crack-initiation sites, degrade mechanical properties, and must be avoided.

Because freckles and misoriented grains develop because of thermosolutal convection, it has been suggested that they will form when a critical Rayleigh number is exceeded. ${ }^{36,38,43,44}$ The Rayleigh number $R a_{s}$ is a measure of the ratio of the buoyancy force to the retarding frictional force in the mushy zone:

$$
R a_{s}=\frac{\left(\Delta \rho / \rho_{o}\right) g K h}{\alpha \nu}
$$

This mean value of the Rayleigh number over the height $h$ of the mushy zone ${ }^{36}$ is dependent on the density gradient in the liquid of $\Delta \rho / \rho_{o}$, average permeability $K$, gravitational acceleration $g$, the thermal diffusivity $\alpha$, and the kinematic viscosity $\nu$. In this form of the expression, the magnitude of the Rayleigh number is proportional to the height of the mushy zone, which in turn varies with the square of the dendrite arm spacing. From this criterion it is apparent that defect occurrence can be avoided by reducing $h$, which is accomplished by increasing the thermal gradient in the process or by reducing the density gradient in the mushy zone. During solidification Re and $\mathrm{W}$ are progressively depleted in the mushy zone, increasing the Rayleigh number, and Ta is progressively enriched (Table 5). These elements all have a strong influence on liquid density, so achieving a balance of Re and W vs Ta or reducing the overall levels of Re and $\mathrm{W}$ will reduce the driving force for convective instabilities. ${ }^{38}$ Unfortunately, these elements are also the most important for strengthening, so there has recently been greater effort aimed at increasing thermal gradients during solidification.

One example of a new approach to increasing thermal gradients during solidification involves the use of liquid-metal coolants (LMCs) during solidification. ${ }^{45}$ Figure 10 shows a schematic of a Bridgman system modified to use liquid tin as a cooling medium. The LMC process using aluminum as the cooling medium has been used in the former USSR for the regular production of aeroengine blades $^{46}$ and is a proven process for smaller aircraft-engine castings. Recent investigations of the process show promising results for single-crystal/columnar-grained castings with substantially larger cross-sections of the type needed for large aircraft engines or industrial gas turbines. ${ }^{47,48}$ Substantial increases in cooling rate and elimination of freckle defects have recently been demonstrated with a liquid-tin LMC process involving directionally solidified castings with cross-sectional areas measuring up to $5 \times 9.5 \mathrm{~cm}$ (Fig. 10). ${ }^{48}$

There are additional defects of concern in cast alloys that are sensitive to the details of the casting geometry and casting procedures and less sensitive to alloy chemistry. These defects include porosity, hot tearing, slivers, and low- and high-angle boundaries (in single crystals). ${ }^{2}$ These defects may limit mechanical properties and are also carefully controlled in specifications and monitored by nondestructive inspection approaches. 
a)
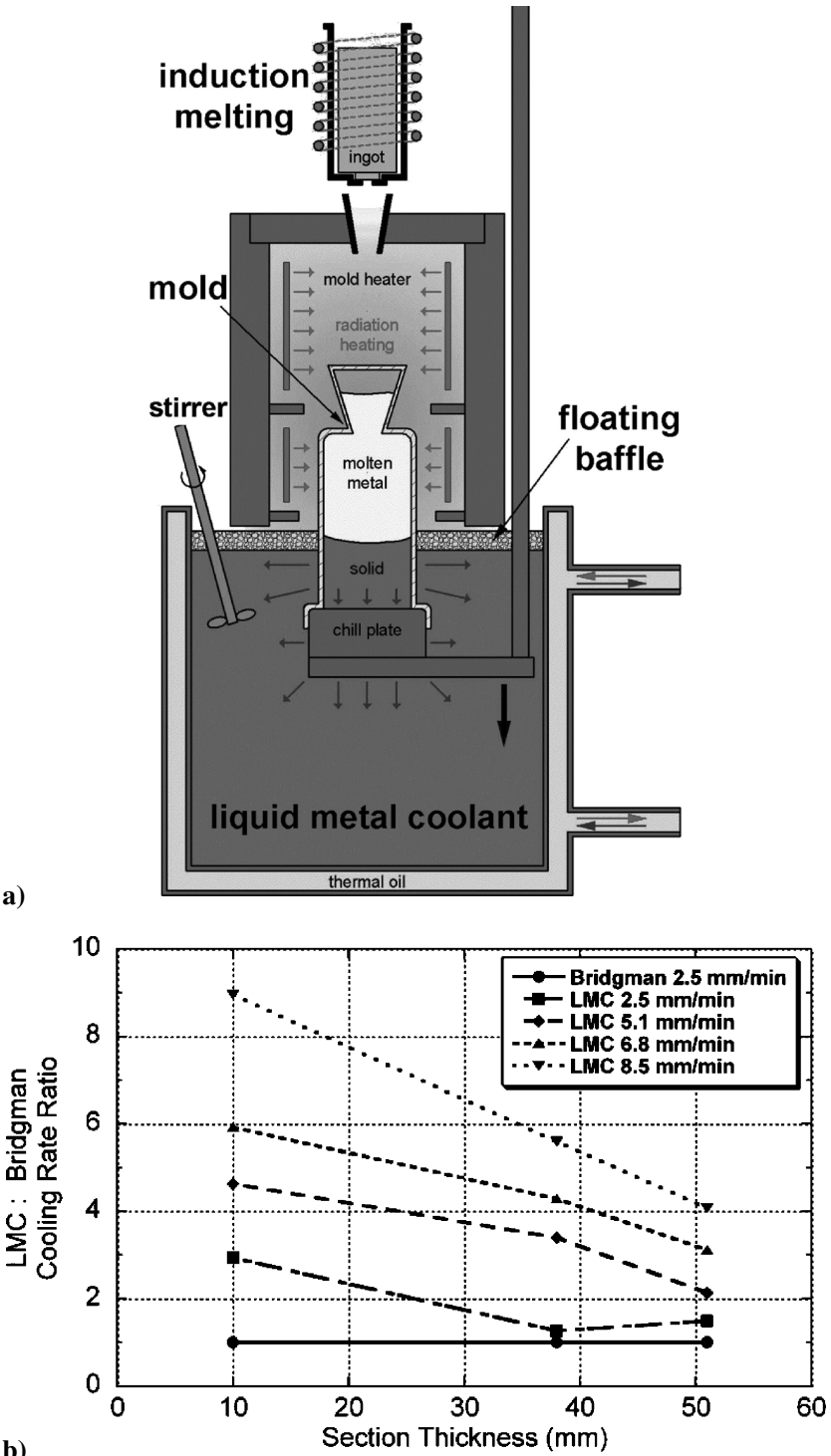

Fig. 10 a) Schematic of the Bridgman process modified to utilize liquid metal cooling (LMC) during unidirectional solidification of Ni-based superalloy components. Note the substantial cooling-rate benefit of the LMC process, compared to b) the conventional Bridgman process.

\section{Wrought Alloys}

As mentioned previously, wrought alloys are typically fabricated by remelting of VIM ingots to form a secondary ingot or powder for subsequent deformation processing. A secondary melting process is necessary for wrought alloys because the high-temperature structural properties of Ni-based superalloys are very sensitive to microstructural variations, chemical inhomogeneities, and inclusions. As ingot sizes increase, VIM melting often results in macrosegregation or the formation of large shrinkage cavities during solidification. The formation of these solidification defects is caused by large-scale solute segregation associated with dendritic solidification under low thermal gradients. Because heat transfer during solidification of VIM ingots is limited by the low intrinsic thermal conductivity of the solidifying mass, large ingots are very prone to the formation of these features. Thus other secondary melting processes are utilized, including vacuum arc remelting (VAR), electro-slag remelting (ESR), and electron beam cold hearth refining (EBCHR). ${ }^{2}$ Here, only the more common VAR process is discussed in the context of avoiding property-reducing defects.

\section{Vacuum Arc Remelting}

For the production of critical rotating components, such as turbine disks, VAR is used to refine the ingot and eliminate macrosegregation. Consumable electrodes ( 30 to $50 \mathrm{~cm}$ in diameter) cast from the VIM charge are remelted into a water-cooled copper crucible. Unlike the VIM process, in which the entire charge of the alloy is molten and allowed to solidify, VAR only involves localized melting of the electrode tip (Fig. 11). Melt rates of VAR are on the order of $\sim 0.5$ to $1 \mathrm{~kg} / \mathrm{s}$. Defect features, such as macrosegregation and shrinkage, are effectively minimized as high thermal gradients are maintained during solidification of the comparatively smaller melt pool. Processing parameters are selected such that the melt pool exhibits a steady-state size and shape. ${ }^{49}$

Although VAR can effectively eliminate the undesirable features of the VIM process, this remelt process may introduce inclusions into the finished ingot. Inclusions in the VAR process may be classified into two groups: extrinsic and intrinsic. Extrinsic inclusions can come from a variety of sources. Incomplete removal of refractory ceramic particles and agglomerates of oxides and nitrides in the revert material used during VIM melting may enable these inclusions to be present in the remelted ingot. As the surface of the VIM ingot is machined to form a consumable electrode, fragments of tungsten carbide cutting tools can be embedded within the ingot. Steel shot used to clean the copper crucible and splash from the previous melt in the VIM crucible may also potentially serve as extrinsic inclusions. With clean melting practices and stringent quality-control measures, many of these extrinsic inclusions can be minimized. Intrinsic inclusions, however, are much more difficult to control during processing and are often dependent upon the chemistry of the alloy.

Thermal and compositional perturbations in the mushy zone during solidification lead to the formation of intrinsic microstructural defects, such as freckles and white spots (Fig. 12). In VAR ingots, freckle defects consist of chains of equiaxed grains aligned parallel to the melt-pool profile or solidification direction. Highly enriched with solute, freckle chains are compositionally different from the bulk alloy and form as a result of thermosolutal convection. ${ }^{43}$ In a process common to many multicomponent superalloys, as soluteaccumulates within the mushy zone during dendritic solidification, the subsequent density imbalance between the solute and bulk liquid serves as a driving force for the onset of convective fluid flow. Upon cooling, the solute-enriched convective instabilities solidify as isolated regions of equiaxed grains. It is important to note that the geometry of the solidification front is more complex in the VAR process as compared to the directional solidification process. For this reason, development of predictive models for the occurrence of freckling is more challenging. White spots are discrete features in the superalloy billet that are observed after chemical etching. ${ }^{50}$ Although compositionally similar, these features are typically less heavily alloyed than the superalloy matrix. Compositions of white spots and freckles in IN718 are listed in Table 6. White-spot formation is commonly attributed to the entrapment of fragments from the melting electrode or crown of the solidifying shelf.

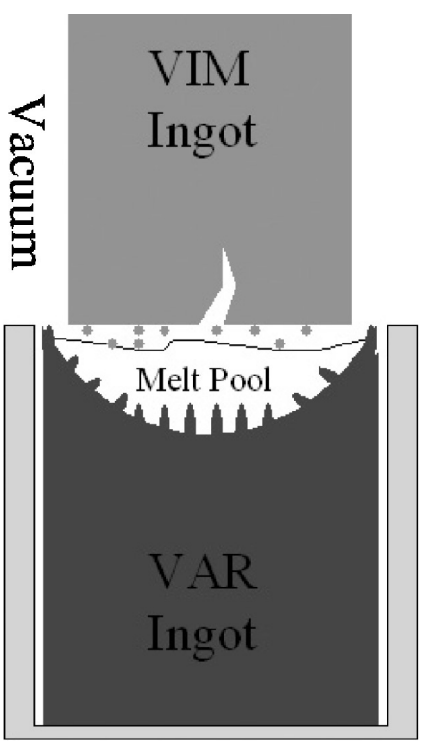

Fig. 11 Schematic of the vacuum arc remelt (VAR) process, using a VIM ingot as input. 


\section{Powder Metallurgy Alloys}

To increase the strength of polycrystalline Ni-based superalloys, levels of refractory alloying additions and $\gamma^{\prime}$-forming elements have gradually increased to levels that make conventional processing routes deficient. ${ }^{51}$ Elements such as $\mathrm{W}, \mathrm{Mo}, \mathrm{Ti}, \mathrm{Ta}$, and $\mathrm{Nb}$ effectively strengthen the alloy but also result in severe segregation within the ingot upon solidification. Additionally, the limited ductility of the high-strength alloys renders the ingot susceptible to cracking as thermally induced stresses evolve during cooling. Powder-processing routes have been developed to overcome the difficulties associated with melt-related defects and are viable for the production of advanced high-strength polycrystalline superalloy components. Listed in Table 1 are the compositions of some commercially available powder-processed $\mathrm{Ni}$-based superalloys.

Table 6 Composition of freckle chains in high-refractory single-crystal superalloys

\begin{tabular}{lcccccrrr}
\hline \hline Composition (wt\%) & $\mathrm{Al}$ & $\mathrm{Cr}$ & $\mathrm{Co}$ & $\mathrm{Hf}$ & $\mathrm{Re}$ & $\mathrm{Ta}$ & $\mathrm{W}$ & $\mathrm{Ni}$ \\
\hline Nominal & 6.0 & 4.5 & 12.5 & 0.16 & 6.3 & 7.0 & 5.8 & Bal. \\
Freckle & 8.2 & 3.6 & 11.0 & 0.18 & 2.3 & 10.0 & 2.9 & Bal. \\
Interdendritic & 7.6 & 4.4 & 12.2 & 0.13 & 3.4 & 8.2 & 3.9 & Bal. \\
\hline \hline
\end{tabular}

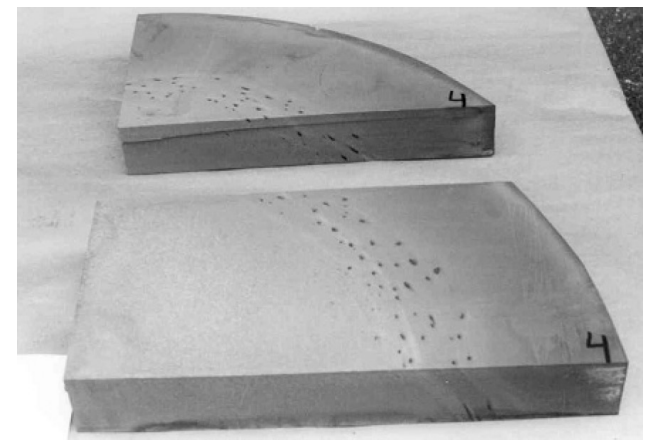

a)

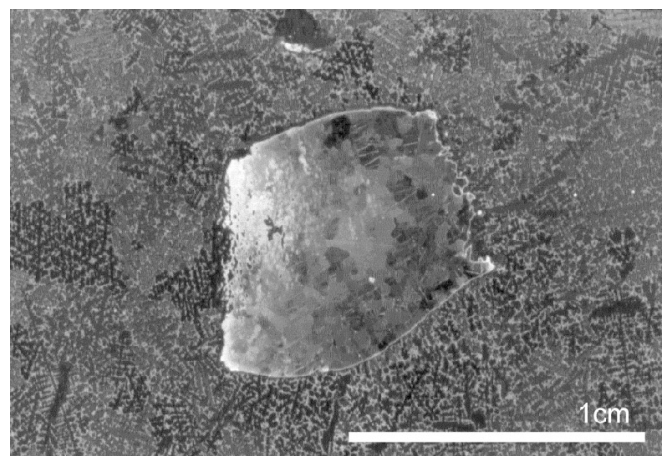

b)

Fig. 12 Freckle and white spot defects in IN718.

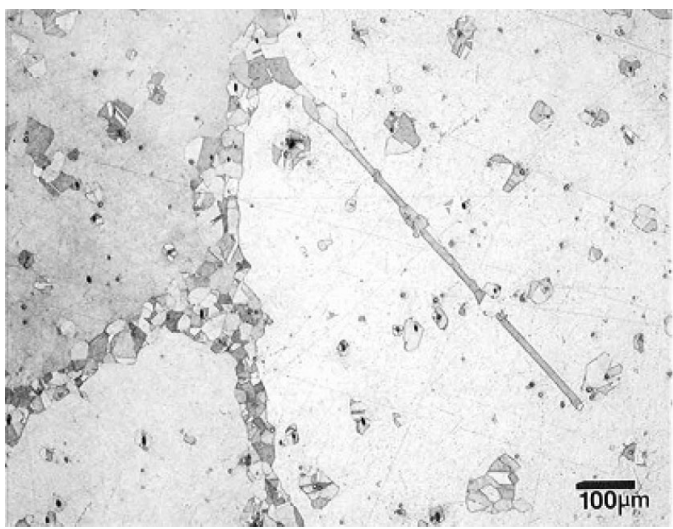

Powder processing begins with gas or vacuum atomization of a highly alloyed VIM ingot. Rapid solidification of the fine powders effectively suppresses macrosegregation within the alloy. Because the low ductility associated with the corresponding high strength causes many of these advanced superalloys to be very sensitive to initial flaw sizes, the atomized powders are separated based on particle size. Standard 150 or 270 meshes are used to separate the powders into sizes $>100 \mu \mathrm{m}$ and $>50 \mu \mathrm{m}$ respectively. Powder sizes directly influence the initial potential crack size present in the finished component. Although finer powder sizes are desired to minimize initial defect sizes, costs increase substantially as yields are substantially reduced.

Once powders are collected into steel cans, the cans are evacuated under vacuum and sealed. The cans are then hot isostatically pressed (HIP) or extruded to consolidate the powder. The HIP process consists of heating the alloy to just below the $\gamma^{\prime}$ solvus temperature under a hydrostatic pressure of up to $310 \mathrm{MPa}$. After 4 to $5 \mathrm{~h}$, diffusion bonding and sintering of the powders under pressure yields a fully dense superalloy billet. Billet sizes are limited by the capacity of the HIP furnace; however, systems capable of forming billets up to $150 \mathrm{~cm}$ in diameter and $300 \mathrm{~cm}$ in height are available. Consolidation under hot extrusion is often preferred over HIP because of the ability to produce fine-grained structures (ASTM 12) and reduce effects associated with prior particle boundaries. The evacuated can containing the superalloy powder is hot extruded through a set of dies that greatly reduces the diameter. During this thermomechanical process, the individual powder particles are subjected to deformation and any oxide films initially present on the surfaces of the powder are broken up. Because substantial plastic deformation and adiabatic heating occurs during this process, hot extrusion temperatures are selected such that temperatures are maintained below the $\gamma^{\prime}$ solvus temperature.

\section{Deformation Processing}

Forging and cogging are common hot-working processes by which superalloy ingots are converted into useful structural components. Because of the high intrinsic strength of Ni-based superalloys, forming of these materials generally occurs at high temperatures $\left(\sim 1000^{\circ} \mathrm{C}\right)$. Hot-working processes are primarily designed to refine the microstructure to yield isotropic properties and attain a near net-shape component. Microstructures in the homogenized ingot are typically extremely coarse (grain sizes $>10 \mathrm{~mm}$ ) and often have a residual columnar-grained structure. Ideally, depending on the application, uniform equiaxed grain sizes on the order of ASTM 12 to $6(5-50 \mu \mathrm{m}$ in diameter) are desired in the forged components. Conversion of the original microstructure into the finegrained structure is achieved via dynamic and metadynamic recrystallization during and after hot working, respectively. ${ }^{52,53}$ Process variables, such as strain, strain rate, and die and workpiece temperature are carefully controlled such that complete recrystallization occurs throughout the material and a uniform microstructure is attained (Fig. 13). Superalloy sheets or small-diameter billets (up to $13 \mathrm{~cm}$ ) can be rolled or forged directly from cast slabs or bars. Prior to the forging of large net-shape superalloy discs for turbine-engine

Fig. 13 Micrographs showing recrystallization of IN718 during hot deformation.

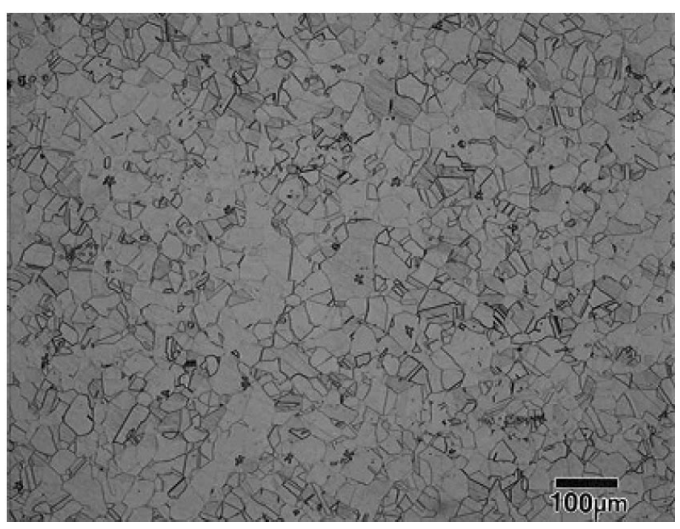




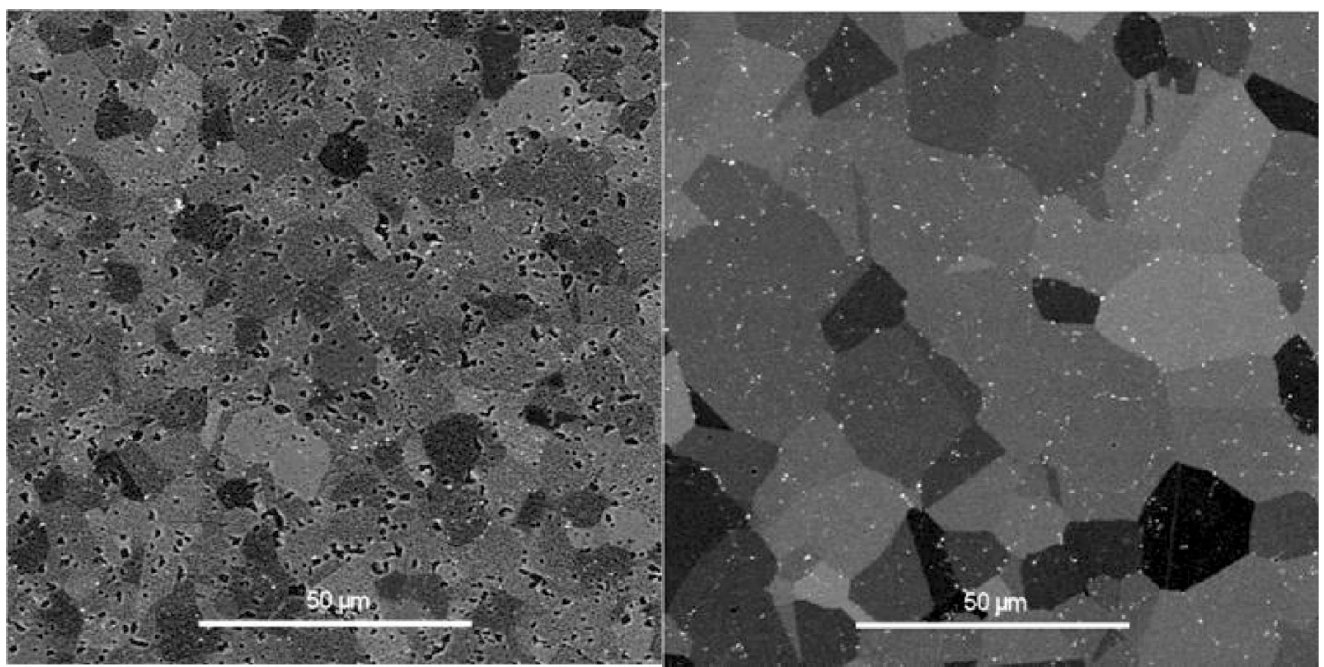

Fig. 14 Microstructures of powder-processed Ni-based superalloys containing elevated levels of refractory alloying additions.

Table 7 Typical physical properties of superalloys

\begin{tabular}{lc}
\hline \hline Property & Typical ranges \\
\hline Density & $7.7-9.0 \mathrm{~g} / \mathrm{cm}^{3}$ \\
Melting temperature (liquidus) & $1320-1450^{\circ} \mathrm{C}$ \\
Elastic modulus & Room temp: $210 \mathrm{GPa}$ \\
& $800^{\circ} \mathrm{C}: 160 \mathrm{GPa}$ \\
Thermal expansion & $8-18 \times 10^{-6} /{ }^{\circ} \mathrm{C}$ \\
Thermal conductivity & Room temp: $11 \mathrm{~W} / \mathrm{m} \cdot \mathrm{K}$ \\
& $800^{\circ} \mathrm{C}: 22 \mathrm{~W} / \mathrm{m} \cdot \mathrm{K}$ \\
\hline \hline
\end{tabular}

applications, large homogenized ingots $(36-60 \mathrm{~cm}$ in diameter) are cogged, or hot worked through a set of open dies, to form billets measuring $15-40 \mathrm{~cm}$. The cogging process assists in breaking down the initial grain structure such that complete recrystallization occurs in the final forging.

One of the major advantages of powder-processed superalloy billets is the initial starting microstructure. Because of the rapid solidification of the powder particles and the negligible amount of elemental segregation within the microstructure, homogenization heat treatments are not required. Powder-consolidation processes also tend to yield a fine equiaxed microstructure in the billet ideal for the direct production of net-shape components (Fig. 14). Conventional forging practices, however, are not ideal for powder-processed $\mathrm{Ni}$ based superalloys. Because of the limited ductility associated with the high levels of refractory alloying elements, isothermal forging of these alloys is generally required. As opposed to conventional forging processes where dies are often cold or warm and strain rates are high, dies used for isothermal forging are at the same temperature as the billet. In most instances, isothermal forging temperatures are maintained just below the $\gamma^{\prime}$ solvus temperature. This enables the fine initial grain sizes to be retained throughout the forging process. The high temperatures combined with the fine grain size and characteristically low strain rates enable the high-strength superalloy to be formed via superplastic flow during isothermal forging.

\section{Properties of Superalloys}

Superalloys constitute a large fraction of the materials of construction in turbine engines because of their unique combination of physical and mechanical properties. Table 7 lists some typical physical properties of superalloys. In aircraft engines, it is typical to consider density-normalized properties; thus alloy densities, which are typically in the range of $7.7-9.0 \mathrm{~g} / \mathrm{cm}^{3}$, are of specific interest. Optimization of the relevant set of mechanical properties is of paramount importance and is dependent on a high level of control and understanding of the processes summarized in Sec. IV, because mechanical properties are a strong function of microstructure. Mechanical properties of primary interest include tensile properties,

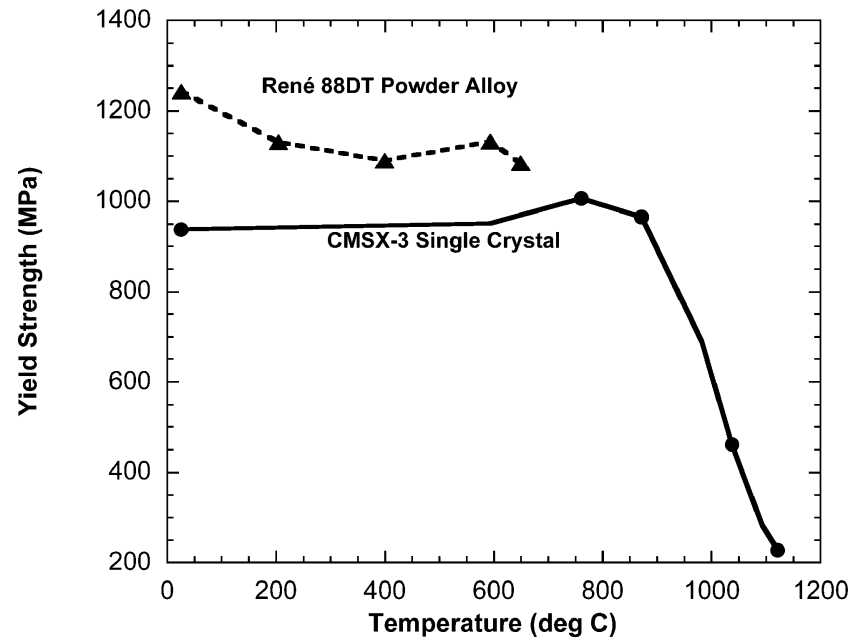

Fig. 15 Plot showing variations in yield strength as a function of temperature for a single-crystal turbine-blade alloy, CMSX-3, and a powder-processed, polycrystalline alloy for turbine-disk applications, Rene' 88 DT.

creep, fatigue, and cyclic crack growth. Depending on the details of component design, any one of these four properties may be life limiting. Each of these properties are briefly discussed in the following sections. It is worth noting that models for prediction of these properties must treat many aspects of microstructure at different length scales. For this reason, predictive models for each of these properties presently remain under development, although in recent years there has been increased effort aimed at property modeling. ${ }^{54}$

\section{A. Tensile Properties}

Nickel-based superalloys have relatively high yield and ultimate tensile strengths, with yield strengths often in the range of 900 $1300 \mathrm{MPa}$ and ultimate tensile strengths of $1200-1600 \mathrm{MPa}$ at room temperature. Figure 15 shows the temperature dependence of the yield strength of a single-crystal alloy and a powder-disk alloy. ${ }^{55,56}$ Turbine-disk alloys are typically developed to have higher strengths for flexibility at temperatures below $800^{\circ} \mathrm{C}$ in the design to protect against burst of the turbine disk in the event of an engine overspeed. Note that the tensile properties do not substantially decay until temperatures are greater than approximately $850^{\circ} \mathrm{C}$. The slight rise in the yield strength of the alloys at intermediate temperatures is due to the unusual flow behavior of the $\mathrm{Ni}_{3} \mathrm{Al} \gamma^{\prime}$ phase. The temperature dependence of yielding in single-phase $\mathrm{Ni}_{3} \mathrm{Al}$, with a strong increase at intermediate temperatures, is shown in Fig. 16. Deformation of the precipitates gives a corresponding, but weaker, rise in the flow stress of superalloys at intermediate temperatures. Note also that the 


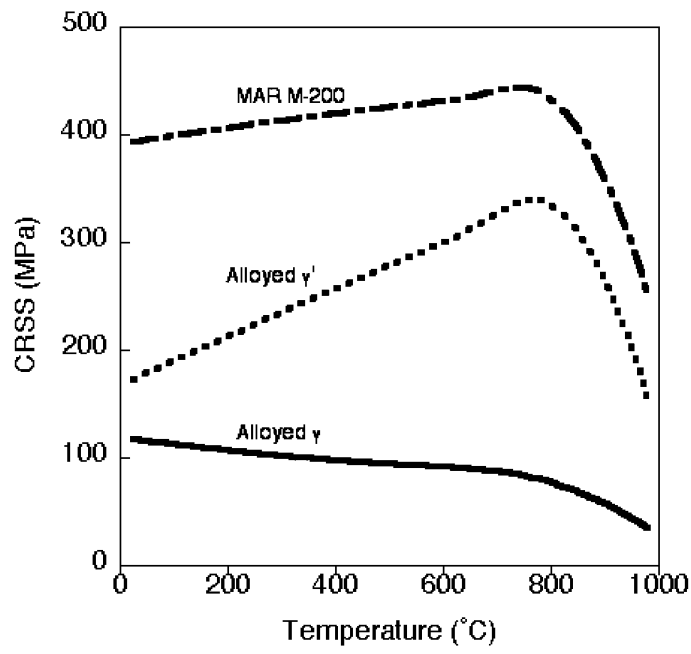

Fig. 16 Comparison of the critical resolved shear stress (CRSS) corresponding to the Ni-based superalloy MAR-M200 and the individual constituent phases (adapted from Ref. 4).

two-phase superalloys are much stronger than either the matrix or precipitate materials in their bulk form (Fig. 16).

Strengthening in two-phase superalloys arises from multiple microstructural sources, including solid-solution strengthening, grainsize strengthening, and the interaction of dislocations with precipitates (Orowan bowing between precipitates or shearing through precipitates in strong- or weak-coupled modes). It is worth noting that heat treatments and various processing steps at different temperatures can result in multiple populations of precipitates with substantially varying mean sizes. ${ }^{12}$ For example, three distinct populations of precipitates in powder IN100 are apparent in Fig. 17, where the microstructure is imaged at various magnifications. The three populations of precipitates are referred to as primary, secondary, and tertiary, in order of decreasing size and precipitation temperature. The primary precipitates are not solutioned in the late stages of processing and therefore inhibit grain growth and indirectly provide grain size strengthening. Disk alloys with these large $(\approx 1 \mu \mathrm{m})$ precipitates are referred to as subsolvus processed. If only one or two populations of submicron-size precipitates are present, because of complete solutioning of the primary $\gamma^{\prime}$, then the grains are much larger $(30-50 \mu \mathrm{m})$; these microstructural conditions result from supersolvus processing. Maximizing strength is a major challenge and requires close attention to all phases of processing. Modeling that considers the various possible strengthening mechanisms for each microstructural constituent in PM IN100 also demonstrates that there is no unique combination of microstructural parameters that results in a high-strength alloy (Fig. 18).

\section{B. Creep Properties}

Because superalloys experience extended periods under stress at high temperature, a high resistance to time-dependent creep deformation is essential. This is very important for cast blade alloys, because they will experience temperatures up to $1100^{\circ} \mathrm{C}$, whereas disk alloys are typically limited to less than $700^{\circ} \mathrm{C}$. For a fixed stress and temperature, two-phase superalloys have a much higher creep resistance compared to their single-phase counterparts (Fig. 19). As with all properties that are governed by plastic deformation processes, creep properties are sensitive to microstructure. Figure 20 shows the creep-rupture life as a function of volume fraction of precipitates for a single crystal alloy. ${ }^{57}$ Note that the strength peaks when the precipitate volume fractions are in the range of $0.6-0.7$. Not surprisingly, many alloys contain volume fractions of precipitates in this peak range. Alloy chemistry is also important to creep properties. Because the rate-controlling processes in creep are diffusion controlled, elements that have low interdiffusion coefficients with nickel are generally beneficial to creep. Interdiffusion for various alloying elements in nickel has recently been studied in detail. ${ }^{58,59}$ Elements most effective at slowing diffusion include Ir, Re, Ru, Pt,
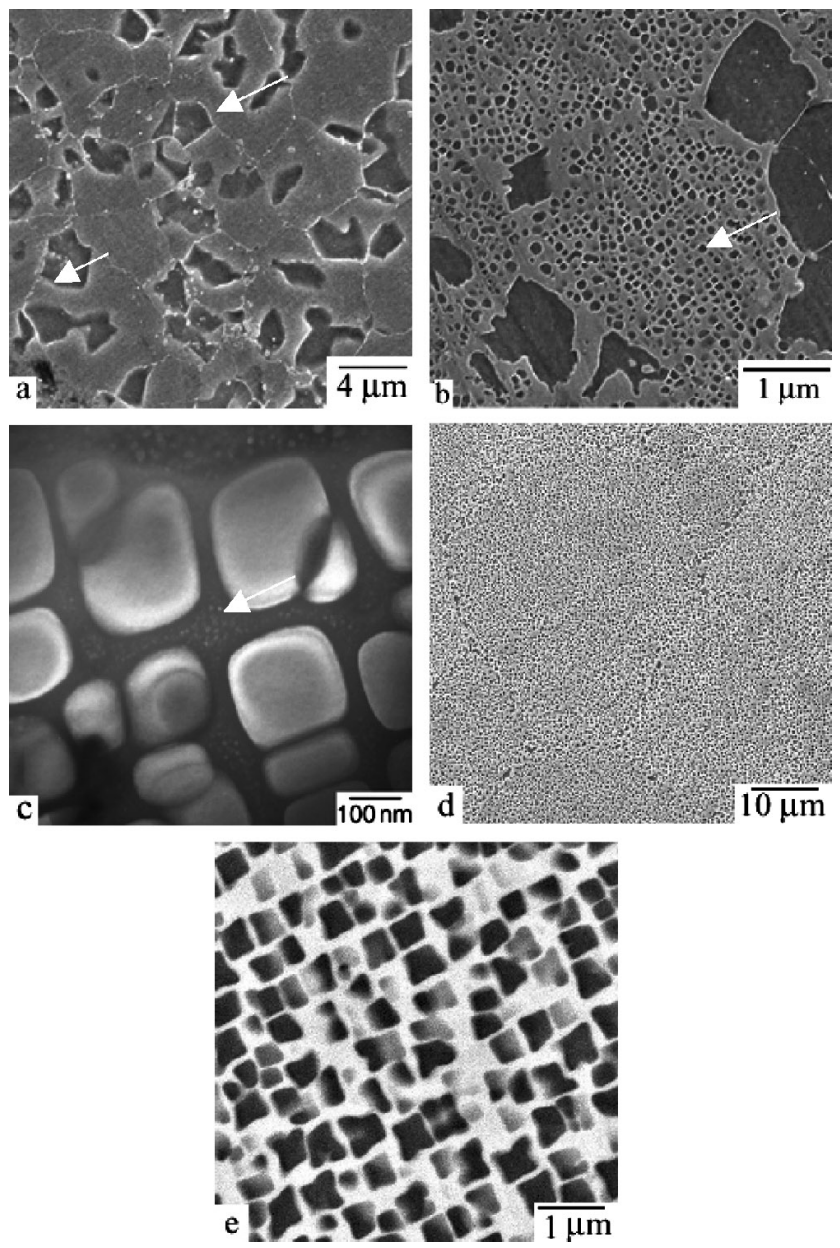

Fig. 17 Microstructure of subsolvus and supersolvus processed IN100.

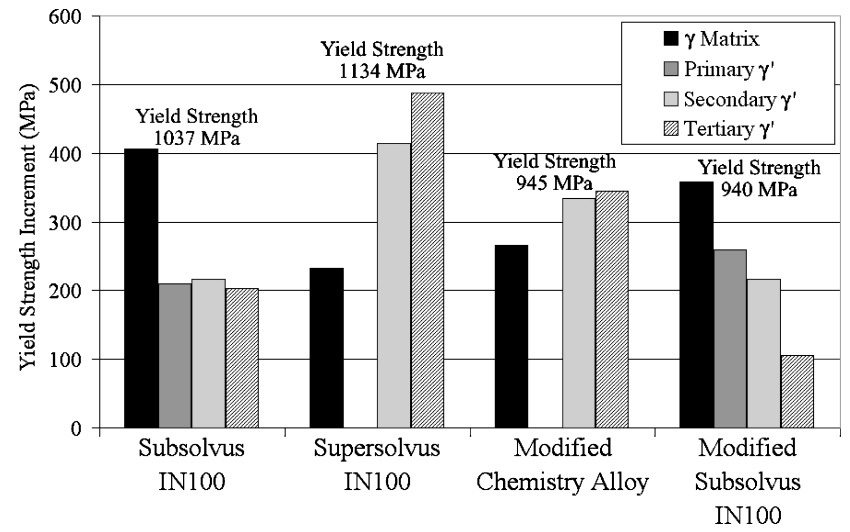

Fig. 18 Dependence of yield strength on microstructure and the strength contributions from the $\gamma$ matrix and $\gamma^{\prime}$ precipitate populations for several variants of IN100. The modified chemistry version of IN100 has somewhat higher levels of $\mathrm{Al}, \mathrm{Cr}$, and $\mathrm{Co}$ and lower levels of $\mathrm{Ti}$ and $\mathrm{V}$ compared to the nominal composition of IN100.

W, Rh, and Mo. Advanced creep-resistant alloys benefit from substantial additions of Re, W, and Mo (Table 1). A combination of increasing refractory alloying additions and advances in processing has resulted in substantial increases in the maximum temperature capability of superalloys over the past few decades. For example, considering a creep-rupture life of $1000 \mathrm{~h}$ at a stress of $137 \mathrm{MPa}$, the most recently developed single-crystal superalloys have a temperature capability of approximately $1100^{\circ} \mathrm{C},{ }^{60}$ whereas conventionally cast equiaxed alloys developed in the 1970s had a temperature capability of $900-950^{\circ} \mathrm{C} .{ }^{61}$ The temperature capabilities have reached $85-90 \%$ of the melting point, an usually high fraction of melting, 


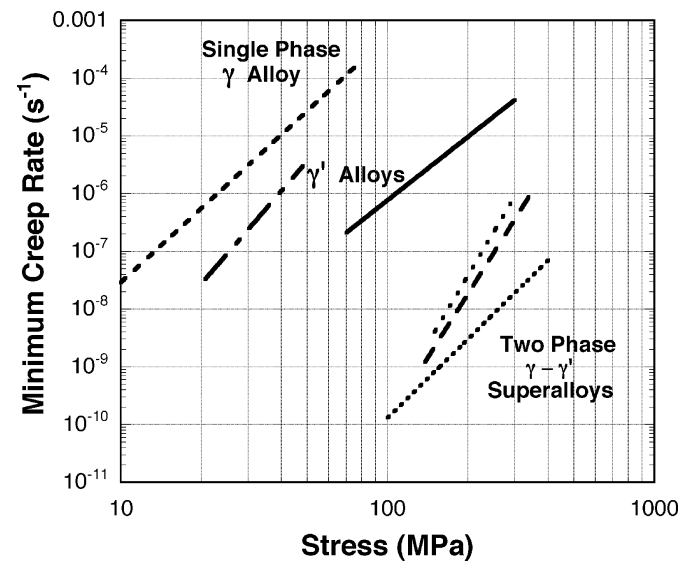

Fig. 19 As reflected by the minimum creep rates, two-phase $\gamma-\gamma^{\prime}$ superalloys exhibit significantly improved creep resistance when compared to their single-phase constituents.

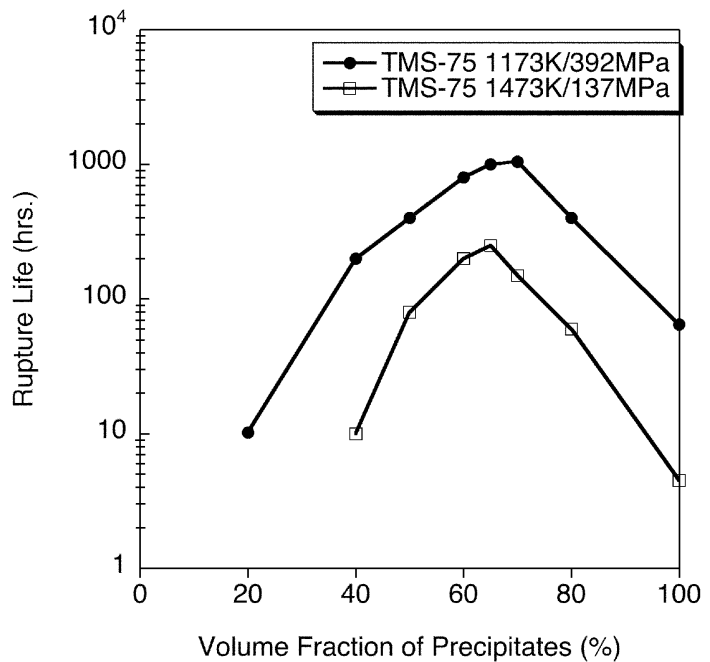

Fig. 20 Variation in creep rupture life as a function of $\gamma^{\prime}$ volume fraction for single crystal TMS-75 (adapted from Ref. 57).

compared to the operating conditions of any other class of structural materials. This indicates a need for development of a completely new class of materials with higher melting points; unfortunately this is a major challenge and there are no obvious replacements for superalloys in the hottest sections of the turbine engine.

The exceptional creep properties are largely due to the fact that the high resistance of the precipitates to shearing extends to elevated temperatures. The uniaxial stress $\sigma_{O R}$ required to glide a dislocation through the narrow matrix channels of the superalloy microstructure is

$$
\sigma_{O R}=\sqrt{\frac{2}{3}}(\mu b / h S)
$$

where $\mu$ is the shear modulus, $b$ is the Burgers vector, $h$ is the width of the channel, and $S$ is the Schmid factor. Typical values of these material properties at $850^{\circ} \mathrm{C}$ are $\mu=48.2 \mathrm{GPa}, b=0.254 \mathrm{~nm}$, and $h=60 \mathrm{~nm}^{23}$ For these parameters, an applied stress of $408 \mathrm{MPa}$ must be exceeded for the onset of dislocation glide through the channels at $850^{\circ} \mathrm{C}$. Thus, this resistance accounts for a large fraction, although not all, of the creep resistance of the two-phase material. Figure 21 shows dislocations gliding through matrix channels during creep of CMSX-3 at $850^{\circ} \mathrm{C}$ and $552 \mathrm{MPa}$.

There have been recent efforts to model the creep behavior of superalloys with the use of continuum damage-mechanics approaches ${ }^{62}$; however, formulating models that capture the essence of the wide array of complex deformation mechanisms remains a challenge. The details of the deformation processes are very sensitive to temperature and applied stress, and it is most convenient to consider mechanisms of creep deformation ${ }^{11}$ at low, intermediate, and high temperatures (and high, intermediate, and low stresses).

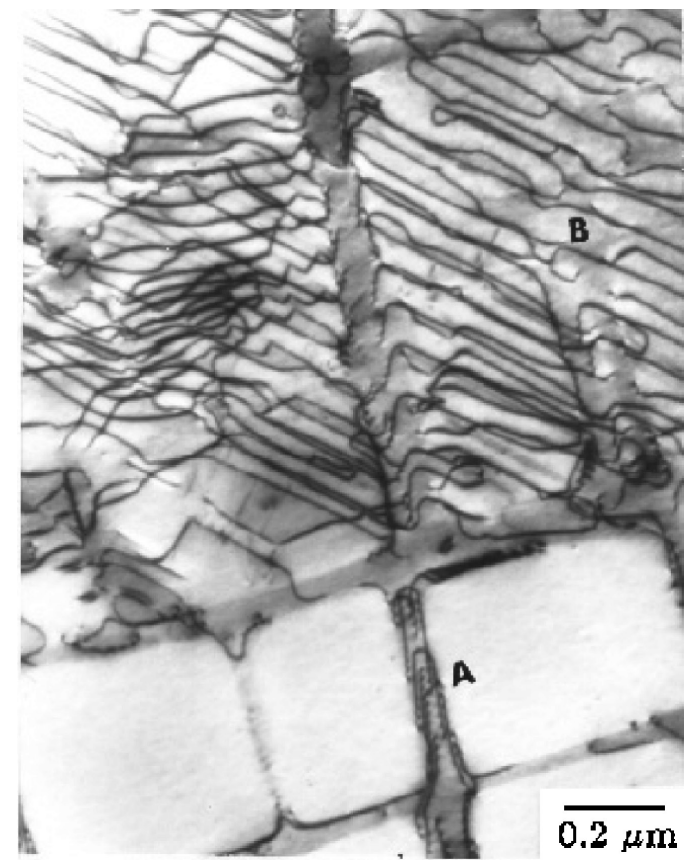

Fig. 21 After an initial incubation period where dislocations fill the horizontal channels, dislocations are forced to bow through the vertical channels because of the high resistance of the precipitates to shearing.

\section{Low-Temperature Creep}

Superalloys are very resistant to creep deformation at temperatures below $800^{\circ} \mathrm{C}$. In general creep deformation occurs by deformation on $\langle 110\rangle\{111\}$ slip systems, with an initial preference for dislocation glide through the continuous matrix. However, at temperatures $<0.6 T_{\mathrm{M}}$, high uniaxial stresses may result in the activation of $\langle 112\rangle\{111\}$ slip systems. ${ }^{56}$ As dislocations accumulate at the $\gamma-\gamma^{\prime}$ interface, $1 / 2\langle 110\rangle$ dislocations undergo reactions that result in $\langle 112\rangle$-type dislocations that are able to penetrate into the $\gamma^{\prime}$ precipitate. The details of the dislocation reactions that result in such precipitate-shearing processes remain under investigation. ${ }^{63}$ Nevertheless, as this shearing process occurs, strain is accumulated rapidly as a result of the planar nature of the slip and can result in high strains during the primary creep transient. This mode of deformation is observed in both single-crystal and polycrystalline alloys during creep. For single crystals, [110]- and [111]-oriented crystals are less prone to this type of deformation, whereas in [001] crystals, planar slip along $\langle 112\rangle$ continues until crystal rotations enable the resolved shear stresses to activate slip on other planes. Other factors that influence these shearing processes include alloy composition, $\gamma^{\prime}$ size, and volume fraction.

\section{Intermediate-Temperature Creep}

At intermediate temperatures, stress levels are typically insufficient to result in shearing of the $\gamma^{\prime}$ precipitates. Thus, deformation within the microstructure is generally confined to the $\gamma$ matrix and results in unusual creep curves that contain an initial incubation period and a brief primary transient, followed by an extended period of accelerating creep. ${ }^{23}$ In general a steady-state creep rate is not achieved.

No macroscopic straining occurs during the incubation period, in part due to the low density of grown-in dislocations. These initial dislocations serve as sources from which dislocations in the $\gamma$ matrix are able to multiply. Single-crystal experiments show that when an external uniaxial stress is applied, the misfit stresses between the $\gamma$ matrix and $\gamma^{\prime}$ precipitate are unbalanced and the effective stresses enable preferential flow of dislocations within the horizontal channels. The incubation period ends when dislocation percolation, initially through the horizontal matrix channels and later through the vertical matrix channels, is complete.

The deformation mechanism associated with the primary creep transient during intermediate-temperature creep is distinctly 


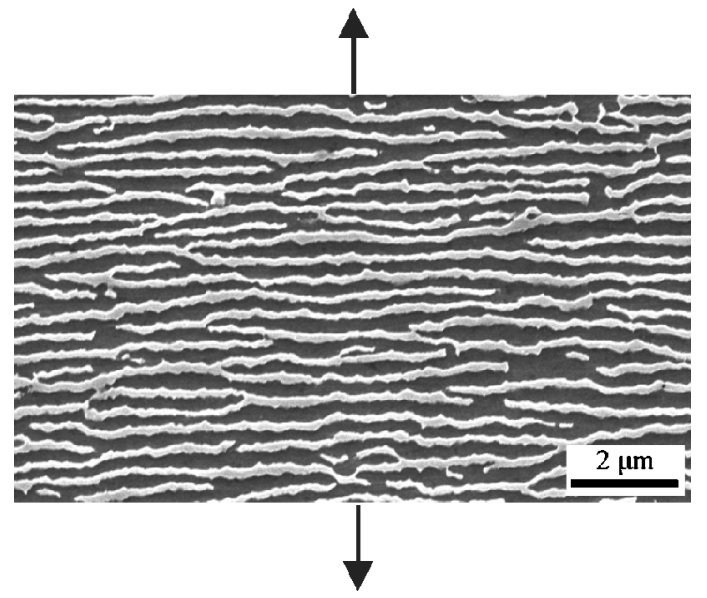

Fig. 22 Directional coarsening at elevated temperatures results in the formation of $\gamma$ rafts aligned perpendicular to the direction of the applied stress. The matrix inverts as the $\gamma$ rafts are contained within a $\gamma^{\prime}$ matrix.

different from that of low-temperature creep. Unlike dislocation shearing of the $\gamma^{\prime}$ precipitates along the $\langle 112\rangle$ direction at high stresses and low temperatures, the primary creep transient at intermediate temperatures can be attributed to the relief of coherency stresses at the $\gamma-\gamma^{\prime}$ interface as dislocations accumulate. At the end of primary creep, a three-dimensional network of dislocations is formed around the precipitates. Despite the lack of a steady-state strain rate, these dislocation networks surrounding the precipitates are extremely stable and contribute to the gradual progression into tertiary creep.

\section{High-Temperature Creep}

The enhanced diffusivity associated with deformation at extremely high temperatures results in morphological changes within the microstructure. With the application of an external stress to alloys with significant precipitate-matrix misfit, the discrete cuboidal $\gamma^{\prime}$ precipitates coalescence into rafts or rods aligned perpendicular or parallel to the applied-stress direction. The kinetics of this directional coarsening process are strongly influenced by the temperature as well as the stresses associated with the coherency strains at the $\gamma-\gamma^{\prime}$ interface. Alignment of the rafts or rods, however, is dependent upon whether the external and misfit stresses are compressive or tensile. For example, uniaxial tensile stresses cause alloys with negative misfit to form rafts perpendicular to the applied-stress direction, whereas compressive stresses applied to the same alloy will result in the formation of rods aligned parallel to the direction of applied stress. Because most commercial directionally solidified and single-crystal alloys exhibit a negative misfit and are used to sustain tensile loads, rafts are generally formed perpendicular to the applied-stress direction (Fig. 22).

With single-crystal and directionally solidified Ni-based superalloys containing in excess of $60 \% \gamma^{\prime}$ by volume, directional coarsening may also result in an inversion of the microstructure. Once rafting is complete, rafts of $\gamma$ are contained within an intermetallic $\gamma^{\prime}$ matrix. Because the rafts of $\gamma$ are discrete, a continuous path for dislocation motion along the matrix channels no longer exists. For deformation to continue, dislocations must shear the $\gamma^{\prime}$ phase. Provided that the rafted structure remains stable, rafted structures are very resistant to deformation at low stresses where dislocations are unable to penetrate into the $\gamma^{\prime}$ matrix. When stresses are sufficient to cause shearing of the $\gamma^{\prime}$ phase, microstructural damage is able to accumulate rapidly and tertiary creep rates are accelerated.

\section{Fatigue and Fatigue Crack Growth}

Turbine-engine components experience significant fluctuations in stress and temperature during their repeated takeoff-cruise-landing cycles. These cycles can result in localized, small, plastic strains. Thus low-cycle, low-frequency fatigue is of interest to engine design. Engine vibrations and airflow between the stages of the turbine

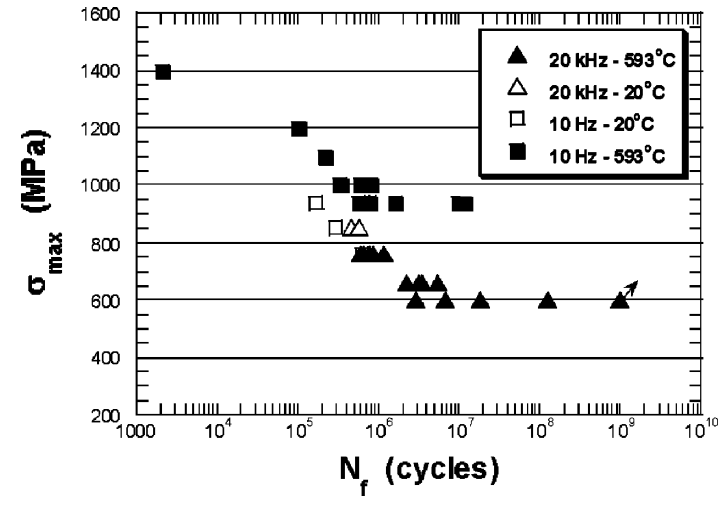

Fig. 23 S-N behavior of Rene' $\mathrm{g8} \mathrm{DT}$ at 20 and $593^{\circ} \mathrm{C}$ at a load ratio of 0.05 at frequencies of $10 \mathrm{~Hz}$ and $20 \mathrm{kHz}$. An arrow indicates a specimen that ran out to $10^{9}$ cycles.

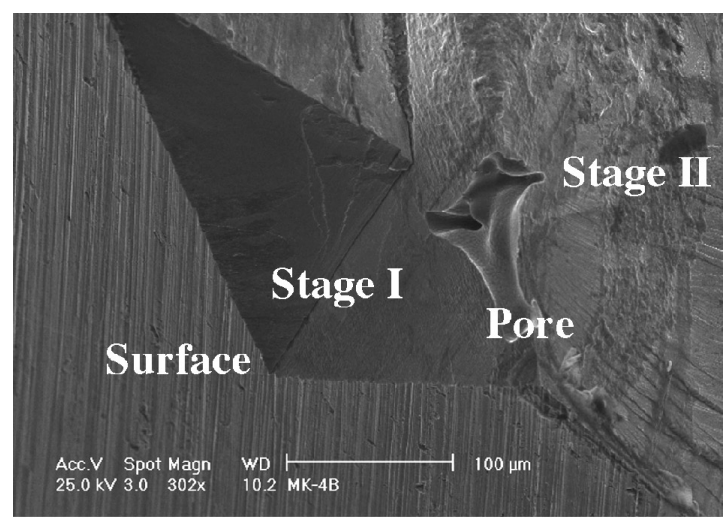

$100 \mu \mathrm{m}$

Fig. 24 Fatigue-crack initiation at a near-surface pore in a singlecrystal superalloy (photo courtesy of L. Rowland).

can also result in high-cycle fatigue with rapid cycle accumulation in airfoils at much higher frequencies, in the $\mathrm{kHz}$ range.

Figure 23 shows fatigue properties for the powder-disk alloy Rene $^{\prime} 88$ DT at room temperature and $593^{\circ} \mathrm{C}$ (Ref. 64). Such polycrystalline-disk alloys exhibit outstanding fatigue properties, with fatigue strengths that are a high fraction of the monotonic yield strength. Under strain-controlled testing conditions in the low-cycle regime, extensive cyclic hardening typically occurs. At lower temperatures, cyclic deformation tends to occur fairly inhomogeneously by shearing of precipitates along $\{111\}$ planes, with dislocations isolated in planar slip bands. ${ }^{65,66}$ As the ease of cross slip increases with temperature, deformation occurs more homogeneously through the microstructure. ${ }^{65}$

Fatigue properties are sensitive to mean stress, particularly at elevated temperatures. A Goodman approach to accounting for mean stresses is often used for component design. ${ }^{67}$ Variability in fatigue lives tends to increase at lower stresses and longer lives in superalloys. An example of this is shown in Fig. 23 for Rene' 88 DT, where fatigue lives at $593^{\circ} \mathrm{C}$ vary between approximately $10^{6}$ cycles and $10^{9}$ cycles at $R=0.05$ and $\sigma_{\max }=600 \mathrm{MPa}$. Such variability may be due to intrinsic variations in microstructure and/or due to the infrequent appearance of extrinsic defects. Crack initiation during fatigue of disk alloys may occur at extrinsic inclusions that are introduced during processing or at specific microstructural features such as larger grains. ${ }^{64}$ In cast alloys, cracks may also initiate at porosity (Fig. 24), carbides, or eutectic. There is a general tendency for initiation to shift from fatigue sample surfaces to subsurface regions in the high-cycle regime, for both equiaxed and single-crystal alloys. ${ }^{67,68}$

Because of stringent safety and associated lifing requirements, fatigue-crack propagation is also an important aspect of material 


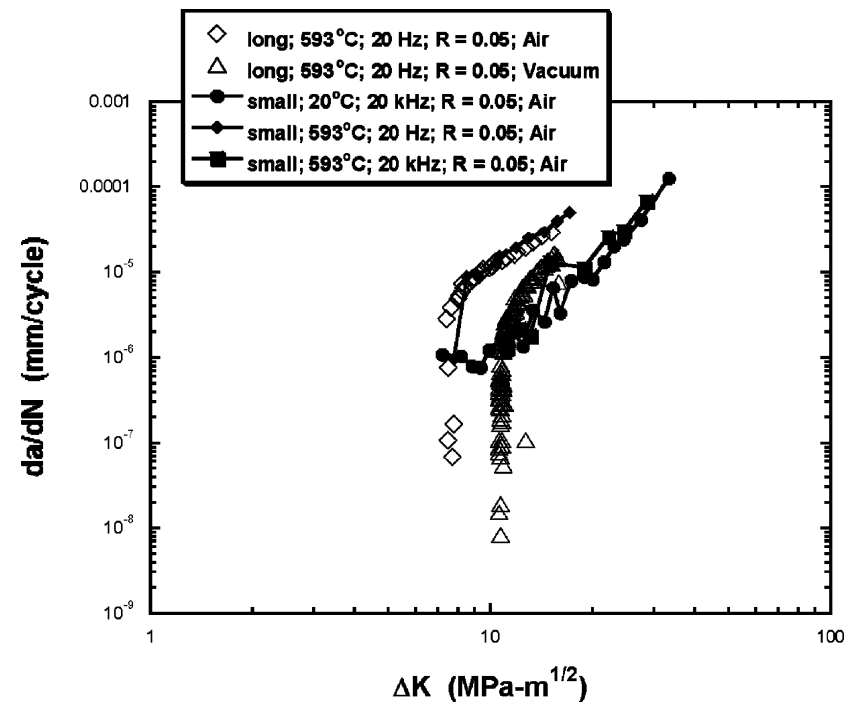

Fig. 25 Fatigue-crack propagation curves at conventional $(20 \mathrm{~Hz})$ and ultrasonic $(20 \mathrm{kHz})$ frequencies for Rene' 88 DT in air and vacuum. Long crack behavior has also been included at a frequency of $20 \mathrm{~Hz}$.

behavior, particularly for turbine-disk materials. Paris law crackgrowth behavior is displayed over a wide range of stress intensities for most superalloys. Cyclic threshold stress intensities are relatively high with $\Delta \mathrm{K}_{\mathrm{th}}$ often in the range of $8-20 \mathrm{MPa} \cdot \mathrm{m}^{1 / 2}$ (Ref. 69). Crack-growth rates are sensitive to microstructural features, including grain size, precipitate sizes, and volume fractions. ${ }^{69}$ At temperatures above approximately $500^{\circ} \mathrm{C}$, environmental effects and cyclic frequency become significant factors, with higher crack-growth rates in air than vacuum. Figure 25 shows an example of fatiguecrack growth behavior for the powder-disk alloy Rene' 88 DT. Note that crack-growth rates are sensitive to test environment and test frequency at $593^{\circ} \mathrm{C}$. In single-crystal alloys, cracks may grow crystallographically along $\{111\}$ planes, particularly in the early stages of growth (stage I). ${ }^{7,69}$ Depending on testing conditions, as cracks grow longer (stage II) they may advance in a less crystallographic manner ${ }^{67,70}$ with a greater tendency toward mode 1 behavior.

Although fatigue and fatigue-crack growth are often limiting properties, comprehensive models for life prediction that account for complex loading, crack initiation, and crack growth as well as microstructure and environment continue to be developed. Integration of physics-based models with advanced sensors that can diagnose the current "damage state" remains a promising approach for component life prediction. ${ }^{71}$

\section{Summary}

Nickel-based superalloys are an exceptional class of structural materials for high-temperature applications and the particularly challenging environment of the turbine section of the aircraft engine. Continued improvements in the properties of these materials have been possible through close control of chemistry and microstructure and the introduction of advanced processing approaches. Further improvements are likely with the development and implementation of tools for alloy design, microstructure-process evolution, and mechanical-property modeling. Integration of the material-design and mechanical-design processes remains an interesting challenge and opportunity.

\section{Acknowledgments}

The authors are grateful for the contributions of a number of their collaborators to this paper, including R. J. Mitchell, A. C. A. Yeh, L. J. Rowland, A. J. Elliott, Q. Feng, R. Kozar, A. Shyam, C. J. Torbet, and J. W. Jones.

\section{References}

${ }^{1}$ Schafrik, R., and Sprague, R., "Saga of Gas Turbine Materials: Part III," Advanced Materials and Processes, Vol. 162, May 2004, pp. 27-30.
${ }^{2}$ Sims, C. T., Stoloff, N. S., and Hagel, W. C., Superalloys II, Wiley, New York, 1986.

${ }^{3}$ Durand-Charre, M., The Microstructure of Superalloys, Gordon and Breach, Amsterdam, 1997.

${ }^{4}$ Loria, E. A., Superalloy 718: Metallurgy and Applications, TMS, Warrendale, PA, 1989.

${ }^{5}$ VerSnyder, F. L., and Shank, M. E., "Development of Columnar Grain and Single Crystal High-Temperature Materials Through Directional Solidification," Materials Science and Engineering, Vol. 6, No. 4, 1970, pp. $213-247$.

${ }^{6}$ Collins, H. E., "Relative Stability of Carbide and Intermetallic Phases in Nickel-Base Superalloys,” Superalloys, ASM, Metals Park, OH, 1968, pp. 171-198.

${ }^{7}$ Crompton, J. S., and Martin, J. W., "Crack Growth in a Single Crystal Superalloy at Elevated Temperature," Metallurgical Transactions A, Vol. 15A, 1984, pp. 1711-1719.

${ }^{8}$ Meetham, G. W., "Trace Elements in Superalloys: An Overview," Metals Technology, Vol. 11, No. 10, 1984, pp. 414-418.

${ }^{9}$ McLean, M., and Strang, A., "Effects of Trace Elements on Mechanical Properties of Superalloys," Metals Technology, Vol. 11, No. 10, 1984, pp. 454-464.

${ }^{10}$ Bouse, G. K., and Mihalisin, J. R., "Metallurgy of Investment Cast Superalloy Compoenents," Superalloys, Supercomposites and Superceramics, edited by J. K. Tien and T. Caulfield, Academic Press, New York, 1989, pp. $99-148$

${ }^{11}$ Pollock, T. M., and Field, R. D., "Dislocations and High Temperature Plastic Deformation of Superalloy Single Crystals," Dislocations in Solids, edited by F. R. N. Nabarro and M. S. Duesbery, Elsevier, Amsterdam, 2002, pp. 549-618.

${ }^{12}$ Wusatowska-Sarnek, A. M., Ghosh, G., Olson, G. B., Blackburn, M. J., and Aindow, M., "Characterization of the Microstructure and Phase Equilibria Calculations for the Powder Metallurgy Superalloy IN100," Journal of Materials Research, Vol. 18, No. 11, 2003, pp. 2653-2663.

${ }^{13}$ Reed, R. C., Yeh, A. C., Tin, S., Babu, S. S., and Miller, M. K., "Identification of the Partitioning Characteristics of Ruthenium in Single Crystal Superalloys Using Atom Probe Tomography," Scripta Materialia, Vol. 51, No. 4, 2004, pp. 327-331

${ }^{14}$ Tien, J. K., and Copley, S. M., "Effect of Orientation and Sense of Applied Uniaxial Stress on the Morphology of Coherent Gamma Prime Precipitates in Stress Annealed Nickel-Base Superalloy Crystals," Metallurgical Transactions, Vol. 2, No. 2, 1971, pp. 543-553.

${ }^{15}$ Grose, D. A., and Ansell, G. S., "The Influence of Coherency Strain on the Elevated Temperature Tensile Behavior of Ni-15Cr-Al-Ti-Mo Alloys," Metallurgical Transactions A, Vol. 12A, No. 9, 1981, pp. 1631-1645.

${ }^{16}$ Pineau, A., "Influence of Uniaxial Stress on the Morphology of Coherent Precipitates During Coarsening-Elastic Energy Considerations," Acta Metallurgica, Vol. 24, No. 6, 1976, pp. 559-564.

${ }^{17}$ Ricks, R. A., Porter, A. J., and Ecob, R. C., "The Growth of Gamma Prime Precipitates in Nickel-Base Superalloys," Acta Metallurgica, Vol. 31, No. 1, 1983, pp. 43-53.

${ }^{18}$ Doi, M., and Miyazaki, T., "Microstructural Development Under the Influence of Elastic Energy in Nickel-Base Alloys Containing Gamma' Precipitates," Superalloys 1988, TMS, Warrendale, PA, 1988, pp. 663-672.

${ }^{19}$ Giamei, A. F., and Anton, D. L., "Rhenium Additions to a Ni-Base Superalloy-Effects on Microstructure," Metallurgical Transactions, Vol. 16A, 1985, pp. 1997-2005.

${ }^{20}$ Fahrmann, M., Hermann, W., Fahrmann, E., Boegli, A., Pollock, T. M., and Sockel, H. G., "Determination of Matrix and Precipitate Elastic Constants in (gamma-gamma') Ni-Base Model Alloys, and Their Relevance to Rafting," Materials Science and Engineering A, Vol. 60, Nos. 1-2, 1999, pp. 212-221.

${ }^{21}$ Nathal, M. V., MacKay, R. A., and Miner, R. V., "Influence of Precipitate Morphology on Intermediate Temperature Creep Properties of a Nickel-Base Superalloy Single Crystal," Metallurgical Transactions A, Vol. 20A, No. 1, 1989, pp. 133-141.

${ }^{22}$ Muller, L., Glatzel, U., and Feller-Kniepmeier, M., "Modelling Thermal Misfit Stresses in Nickel-Base Superalloys Containing High Volume Fraction of Gamma' Phase," Acta Metallurgia et Materialia, Vol. 41, 1992, pp. 3401-3411.

${ }^{23}$ Pollock, T. M., and Argon, A. S., "Creep Resistance of CMSX-3 Nickel Base Superalloy Single Crystals," Acta Metallurgia et Materialia, Vol. 40, No. 6, 1992, pp. 1-30.

${ }^{24}$ Ross, E. W., "Rene 100-A Sigma-Free Turbine Blade Alloy," Journal of Metals, Vol. 19, No. 12, 1967, pp. 12-14.

${ }^{25}$ Nystrom, J. D., Pollock, T. M., Murphy, W. H., and Garg, A., "Discontinuous Cellular Precipitation in a High-Refractory Nickel-Base Superalloy," Metallurgical and Materials Transactions, Vol. 28A, 1997, pp. 2443-2452.

${ }^{26}$ Wlodek, S. T., “The Structure of IN100," Transactions ASM, Vol. 57, 1964, pp. 110-119. 
${ }^{27}$ Rae, C. M. F., and Reed, R. C., "The Precipitation of Topologically Close-Packed Phases in Rhenium-Containing Superalloys," Acta Materialia, Vol. 49, No. 10, 2001, pp. 4113-4125.

${ }^{28}$ Darolia, R., Lahrman, D. F., and Field, R. D., "Formation of Topologically Closed Packed Phases in Nickel Base Single Crystal Superalloys," Superalloys 1988, TMS, Warrendale, PA, 1988, pp. 255-264.

${ }^{29}$ Agren, J., "Calculation of Phase Diagrams: Calphad," Current Opinion in Solid State and Materials Science, Vol. 1, 1996, pp. 355-360.

${ }^{30}$ Kattner, U. R., "Thermodynamic Modeling of Multicomponent Phase Equilibria," Journal of Metals, Vol. 49, No. 12, 1997, pp. 14-19.

${ }^{31}$ Saunders, N., Fahrmann, M., and Small, C. J., "The Application of CALPHAD Calculations to Ni-Based Superalloys," Superalloys 2000, TMS, Warrendale, PA, 2000, pp. 803-811.

${ }^{32}$ Wu, K., Chang, Y. A., and Wang, Y., "Simulating Interdiffusion Microstructures in Ni-Al-Cr Diffusion Couples: A Phase Field Approach Coupled with CALPHAD Database," Scripta Materialia, Vol. 50, 2004, pp. $1145-1150$.

${ }^{33}$ Tien, J. K., and Caulfield, T., Superalloys, Supercomposites and Superceramics, Academic Press, New York, 1988.

${ }^{34}$ Tin, S., Pollock, T. M., and Murphy, W., "Stabilization of Thermosolutal Convective Instabilities in Ni-Based Single Crystal Superalloys: Carbon Additions and Freckle Formation," Metallurgical and Materials Transactions, Vol. 32A, No. 7, 2001, pp. 1743-1753.

${ }^{35}$ Tin, S., and Pollock, T. M., "Predicting Freckle Formation in Single Crystal Ni-Base Superalloys," Journal of Materials Science, Vol. 39, No. 24, 2004, pp. 7199-7205.

${ }^{36}$ Beckermann, C., Gu, J. P., and Boettinger, W. J., "Development of a Freckle Predictor via Rayleigh Number Method for Single-Crystal Superalloy Castings," Metallurgical and Materials Transactions, Vol. 31A, No. 10, 2000, pp. 2545-2557.

${ }^{37}$ Wang, W., Lee, P. D., and McLean, M., “A Model of Solidification Microstructures in Nickel-Based Superalloys: Predicting Primary Dendrite Spacing Selection," Acta Materialia, Vol. 51, No. 10, 2003, pp. 2971-2987.

${ }^{38}$ Pollock, T. M., and Murphy, W. H., "The Breakdown of Solidification in High Refractory Nickel-Base Superalloys," Metallurgical and Materials Transactions, Vol. 27A, No. 4, 1996, pp. 1081-1094.

${ }^{39}$ Giamei, A. F., and Kear, B. H., "Nature of Freckles in Nickel-Base Superalloys," Metallurgical Transactions A, Vol. 1, 1970, pp. 2185-2192.

${ }^{40}$ Copley, S. M., Giamei, A. F., Johnson, S. M., and Hornbecker, M. F., "Origin of Freckles in Unidirectionally Solidified Castings," Metallurgical Transactions A, Vol. 1, No. 8, 1970, pp. 2193-2204.

${ }^{41}$ Sample, A. K., and Hellawell, A., "The Mechanisms of Formation and Prevention of Channel Segregation During Alloy Solidification," Metallurgical Transactions A, Vol. 15A, 1984, pp. 2163-2173.

${ }^{42}$ Schneider, M. C., Gu, J. P., Beckermann, C., Boettinger, W. J., and Kattner, U. R., "Modeling of Micro- and Macrosegregation and Freckle Formation in Single Crystal Nickel-Base Superalloy During Directional Solidification," Metallurgical Transactions A, Vol. 28A, No. 7, 1997, pp. 1517-1531.

${ }^{43}$ Auburtin, P., Cockcroft, S. L., and Mitchell, A., "Freckle Formation in Superalloys," Superalloys 1996, TMS, Warrendale, PA, 1996, pp. 443-450.

${ }^{44}$ Sarazin, J. R., and Hellawell, A., "Channel Formation in Pb-Sn, Pb-Sb and $\mathrm{Pb}-\mathrm{Sn}$-Sb Alloy Ingots and Comparison with the System $\mathrm{NH}_{4} \mathrm{Cl}-\mathrm{H}_{2} \mathrm{O}$," Metallurgical Transactions A, Vol. 19A, 1988, pp. 1861-1871.

${ }^{45}$ Giamei, A. F., and Tschinkel, J. G., "Liquid Metal Cooling-A New Solidification Technique," Metallurgical Transactions A, Vol. 7A, Sept. 1976, pp. $1427-1434$.

${ }^{46}$ Hugo, F., Betz, U., Ren, J., Huang, S.-C., Bondarenko, J. A., and Gerasimov, V., "Casting of Directionally Solidified and Single Crystal Components Using Liquid Metal Cooling (LMC): Results from Experimental Trials and Computer Simulations," Proceedings of the International Symposium on Liquid Metal Processing and Casting, AVS, 1999, pp. $16-30$

${ }^{47}$ Lohmuller, A., Esser, W., Gossmann, Hordler, M., Preuhs, J., and Singer, R. F., "Improved Quality and Economics of Investment Castings by Liquid Metal Cooling-The Selection of Cooling Media," Superalloys 2000, TMS, Warrendale, PA, 2000, pp. 181-188.

${ }^{48}$ Elliott, A. J., Tin, S., King, W. T., Huang, S.-C., Gigliotti, M. F. X., and Pollock, T. M., "Directional Solidification of Large Superalloy Castings with Radiation and Liquid-Metal Cooling: A Comparative Assessment," Metallurgical and Materials Transactions A, Vol. 35A, No. 10, 2004, pp. 3221-3231.

${ }^{49}$ Kermanapur, A., Evans, D. G., Siddall, R. J., Lee, P. D., and McLean, M., "Effect of Process Parameters on Grain Structure Formation During
VAR of Inconel Alloy 718," Journal of Materials Science, Vol. 39, No. 24, 2004, pp. 7175-7182.

${ }^{50}$ Jackman, L. A., Maurer, G. E., and Widge, S., "New Knowledge About 'White Spots' in Superalloys," Advanced Materials and Processes, Vol. 143, No. 5, 1993, pp. 18-25.

${ }^{51}$ Maurer, G. E., Castledine, W., Schweizer, F. A., and Mancuso, S., "Development of HIP Consolidated P/M Superalloys for Conventional Forging to Gas Turbine Components," Superalloys 1996, TMS, Warrendale, PA, 1996, pp. 645-652.

${ }^{52}$ Luton, M. J., and Sellars, C. M., "Dynamic Recrystallization in Nickel and Nickel-Iron Alloys During High Temperature Deformation," Acta Metallurgica, Vol. 17, No. 8, 1969, pp. 1033-1043.

${ }^{53}$ Shen, S., Semiatin, S. L., and Shivpuri, R., "Modeling Microstructural Development During the Forging of Waspaloy," Metallurgical and Materials Transactions, Vol. 26A, No. 7, 1995, p. 1795

${ }^{54}$ Backman, D. G., Mourer, D. P., Bain, K. R., and Walston, W. S., "AIMA New Methodology for Developing Disk Materials," Advanced Materials and Processes for Gas Turbines, TMS, Warrendale, PA, 2003, pp. 255-264.

${ }^{55}$ Huron, E.S., "Serrated Yielding in a Nickel-Base Superalloy," Superalloys 1992, TMS, Warrendale, PA, 1992, pp. 675-684.

${ }^{56}$ Pollock, T. M., and Field, R. D., "Dislocations and High Temperature Plastic Deformation of Superalloy Single Crystals," Dislocations in Solids, Vol. 11, edited by F. R. N. Nabarro and M. S. Duesbery, Elsevier, Amsterdam, 2002, pp. 549-618.

${ }^{57}$ Murakumo, T., Kobayashi, T., Koizumi, Y., and Harada, H., "Creep Behavior of Ni-Base Single-Crystal Superalloys with Various Gamma' Volume Fraction," Acta Materialia, Vol. 52, No. 12, 2004, pp. 3737-3744.

${ }^{58}$ Karunarante, M. S. A., and Reed, R. C., "Interdiffusion of PlatinumGroup Metals in Nickel at Elevated Temperatures," Acta Materialia, Vol. 51, No. 10, 2003, pp. 2905-2914.

${ }^{59}$ Reed, R. C., and Karunarantne, M. S. A., "Interdiffusion in the FaceCentered Cubic Phase of Ni-Re, Ni-Ta and Ni-W Systems Between $900^{\circ} \mathrm{C}$ and $1300^{\circ}$ C," Materials Science and Engineering A, Vol. 281, Nos. 1-2, 2000, pp. 229-233.

${ }^{60}$ Walston, W. S., Cetel, A., MacKay, R., O'Hara, K., Duhl, D., and Dreshfield, R., "Joint Development of a Fourth Generation Single Crystal Superalloy," Superalloys 2004, TMS, Warrendale, PA, 2004, pp. 15-24.

${ }^{61}$ Tanaka, R., "Research and Development of Ultra-High Temperature Materials in Japan," Materials at High Temperatures, Vol. 17, No. 4, 2000, pp. 457-464.

${ }^{62}$ McLean, M., and Dyson, B. F., "Modeling the Effects of Damage and Microstructural Evolution on the Creep Behavior of Engineering Alloys," Journal of Engineering Materials and Technology, Vol. 122, 2000, pp. 273-278.

${ }^{63}$ Rae, C. M. F., Cox, D. C., Rist, M. A., Reed, R. C., and Matan, N. C., "On the Primary Creep of CMSX-4 Superalloy Single Crystals," Metallurgical and Materials Transactions A, Vol. 31A, No. 9, 2000, pp. 2219-2228.

${ }^{64}$ Shyam, A., Torbet, C. J., Jha, S. K., Larsen, J. M., Caton, M. J., Szczepanski, C. J., Pollock, T. M., and Jones, J. W., "Development of Ultrasonic Fatigue for Rapid, High Temperature Fatigue Studies in Turbine Engine Materials," Superalloys 2004, TMS, Warrendale, PA, 2004, pp. 259-267.

${ }^{65}$ Miner, R. V., Gayada, J., and Maier, R. D., "Fatigue and Creep Fatigue Deformation of Several Nickel-Base Superalloys at $650^{\circ} \mathrm{C}$," Metallurgical Transactions A, Vol. 13A, No. 10, 1982, pp. 1755-1765.

${ }^{66}$ Clavel, M., and Pineau, A., "Fatigue Behavior of Two Nickel-Base Alloys I: Experimental Results on Low Cycle Fatigue, Fatigue Crack Propagation and Substructures," Materials Science and Engineering, Vol. 55, No. 2, 1982, pp. 157-171.

${ }^{67}$ Chan, K. S., Hack, J. E., and Leverant, G. R.,"Fatigue Crack Growth in Mar-M200 Single Crystals," Metallurgical Transactions, Vol. 18A, No. 4, 1987, pp. 581-591.

${ }^{68}$ Antolovich, S. D., and Lerch, B., "Cyclic Deformation, Fatigue and Fatigue Crack Propagation in Ni-Base Alloys," Superalloys, Supercomposites and Superceramics, edited by J. K. Tien and T. Caulfield, Academic Press, New York, 1989, pp. 363-412.

${ }^{69}$ Wright, P. K., Jain, M., and Cameron, D., "High Cycle Fatigue in a Single Crystal Superalloy: Time Dependence at Elevated Temperature," Superalloys 2004, TMS, Warrendale, PA, 2004, pp. 657-666.

${ }^{70}$ Crompton, J. S., and Martin, J. W., "Crack Growth in a Single Crystal Superalloy at Elevated Temperature," Metallurgical Transactions A, Vol. 15A, 1984, pp. 1711-1718.

${ }^{71}$ Larsen, J. M., and Christodoulou, "Using Materials Prognosis to Maximize the Utilization of Complex Mechanical Systems," Journal of Metals, Vol. 56, No. 3, 2004, pp. 15-19. 